Atmos. Chem. Phys., 17, 14309-14332, 2017

https://doi.org/10.5194/acp-17-14309-2017

(c) Author(s) 2017. This work is distributed under

the Creative Commons Attribution 3.0 License.

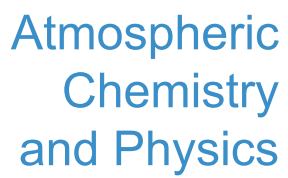

(c) (i)

\title{
Boreal forest BVOC exchange: emissions versus in-canopy sinks
}

\author{
Putian Zhou $^{1}$, Laurens Ganzeveld ${ }^{2}$, Ditte Taipale ${ }^{3,4}$, Üllar Rannik ${ }^{1}$, Pekka Rantala ${ }^{1}$, Matti Petteri Rissanen ${ }^{1}$, \\ Dean Chen ${ }^{1}$, and Michael Boy ${ }^{1}$ \\ ${ }^{1}$ University of Helsinki, Department of Physics, P.O. Box 64, 00014, University of Helsinki, Helsinki, Finland \\ ${ }^{2}$ Meteorology and Air Quality (MAQ), Department of Environmental Sciences, Wageningen University and Research Centre, \\ Wageningen, the Netherlands \\ ${ }^{3}$ University of Helsinki, Department of Forest Sciences, P.O. Box 27, 00014, University of Helsinki, Helsinki, Finland \\ ${ }^{4}$ Estonian University of Life Sciences, Department of Plant Physiology, Kreutzwaldi 1, 51014, Estonia
}

Correspondence to: Putian Zhou (putian.zhou@helsinki.fi)

Received: 23 May 2017 - Discussion started: 7 July 2017

Revised: 23 October 2017 - Accepted: 26 October 2017 - Published: 4 December 2017

\begin{abstract}
A multilayer gas dry deposition model has been developed and implemented into a one-dimensional chemical transport model SOSAA (model to Simulate the concentrations of Organic vapours, Sulphuric Acid and Aerosols) to calculate the dry deposition velocities for all the gas species included in the chemistry scheme. The new model was used to analyse in-canopy sources and sinks, including gas emissions, chemical production and loss, dry deposition, and turbulent transport of 12 featured biogenic volatile organic compounds (BVOCs) or groups of BVOCs (e.g. monoterpenes, isoprene+2-methyl-3-buten-2-ol (MBO), sesquiterpenes, and oxidation products of mono- and sesquiterpenes) in July 2010 at the boreal forest site SMEAR II (Station for Measuring Ecosystem-Atmosphere Relations). According to the significance of modelled monthly-averaged individual source and sink terms inside the canopy, the selected BVOCs were classified into five categories:
\end{abstract}

1. Most of emitted gases are transported out of the canopy (monoterpenes, isoprene $+\mathrm{MBO}$ ).

2. Chemical reactions remove a significant portion of emitted gases (sesquiterpenes).

3. Bidirectional fluxes occur since both emission and dry deposition are crucial for the in-canopy concentration tendency (acetaldehyde, methanol, acetone, formaldehyde).

4. Gases removed by deposition inside the canopy are compensated for by the gases transported from above the canopy (acetol, pinic acid, $\beta$-caryophyllene's oxidation product $\mathrm{BCSOZOH}$ ).

5. The chemical production is comparable to the sink by deposition (isoprene's oxidation products ISOP34OOH and ISOP34NO3).

Most of the simulated sources and sinks were located above about $0.2 h_{\mathrm{c}}$ (canopy height) for oxidation products and above about $0.4 h_{\mathrm{c}}$ for emitted species except formaldehyde. In addition, soil deposition (including deposition onto understorey vegetation) contributed $11-61 \%$ to the overall in-canopy deposition. The emission sources peaked at about $0.8-0.9 h_{\mathrm{c}}$, which was higher than $0.6 h_{\mathrm{c}}$ where the maximum of dry deposition onto overstorey vegetation was located.

This study provided a method to enable the quantification of the exchange between atmosphere and biosphere for numerous BVOCs, which could be applied in large-scale models in future. With this more explicit canopy exchange modelling system, this study analysed both the temporal and spatial variations in individual in-canopy sources and sinks, as well as their combined effects on driving BVOC exchange. In this study 12 featured BVOCs or BVOC groups were analysed. Other compounds could also be investigated similarly by being classified into these five categories. 


\section{Introduction}

Boreal forests emit a large number of biogenic volatile organic compounds (BVOCs), which include monoterpenes $\left(\mathrm{C}_{10} \mathrm{H}_{16}\right)$, isoprene $\left(\mathrm{C}_{5} \mathrm{H}_{8}\right)$, sesquiterpenes $\left(\mathrm{C}_{15} \mathrm{H}_{24}\right)$, methanol $\left(\mathrm{CH}_{3} \mathrm{OH}\right)$, acetone $\left(\mathrm{CH}_{3} \mathrm{C}(\mathrm{O}) \mathrm{CH}_{3}\right)$, acetaldehyde $\left(\mathrm{CH}_{3} \mathrm{CHO}\right)$, and many others (Rinne et al., 2009; Guenther et al., 2006, 2012). Once emitted, BVOCs in the atmosphere can be transformed by reacting with the hydroxyl radical $(\mathrm{OH})$, ozone $\left(\mathrm{O}_{3}\right)$, or nitrate radical $\left(\mathrm{NO}_{3}\right)$, producing oxygenated volatile organic compounds (OVOCs). The OVOCs can be oxidized to carbon monoxide ( $\mathrm{CO}$ ) or carbon dioxide $\left(\mathrm{CO}_{2}\right)$ by further chemical reactions, participate in secondary organic aerosol (SOA) formation, or deposit onto surfaces (Goldstein and Galbally, 2007).

BVOC emissions from boreal pine forests have been investigated extensively in previous studies (e.g. Taipale et al., 2011; Bäck et al., 2012; Aalto et al., 2014). For example, the seasonal branch-scale measurements of emissions of monoterpenes and sesquiterpenes from Scots pine trees were reported in Tarvainen et al. (2005) and Hakola et al. (2006). More compounds in addition to monoterpenes, including methanol, acetaldehyde, and acetone, were measured by Rinne et al. (2007) on an ecosystem scale. Recently, Rantala et al. (2015) revised the fluxes of isoprene, monoterpenes, and several OVOCs over a boreal forest canopy based on long-term measurements from 2010 to 2013. In addition, the boreal forest floor also plays a significant role in BVOC exchange (e.g. Mäki et al., 2017). Aaltonen et al. (2011) reported the emissions of monoterpenes $\left(5 \mu \mathrm{g} \mathrm{m}^{-2} \mathrm{~h}^{-1}\right)$, isoprene $\left(0.050 \mu \mathrm{g} \mathrm{m}^{-2} \mathrm{~h}^{-1}\right)$, and sesquiterpenes $\left(0.045 \mu \mathrm{g} \mathrm{m}^{-2} \mathrm{~h}^{-1}\right)$ from ground vegetation and soil. Compared to the ecosystem-scale fluxes, the fluxes of BVOCs (e.g. methanol, acetaldehyde, acetone, and monoterpenes) from the forest floor were about 1 to 2 orders of magnitude lower (Aaltonen et al., 2013).

The BVOCs emitted or produced by chemical reactions are dispersed by turbulent air motion, possibly being taken up by vegetation surfaces, which is controlled by different dry deposition pathways, or being transported throughout the planetary boundary layer. The majority of the BVOCs diffuse between the ambient air and intercellular air space via stomata with the direction of this exchange being dependent on the concentration gradient. For those BVOCs being metabolized rapidly, enzymatically or non-enzymatically, in the intercellular air space one would anticipate stomatal deposition with the uptake rate to be determined by stomatal conductance. For those BVOCs with a less efficient intercellular air space destruction or actually a production mechanism, the actual direction and efficiency of the stomatal exchange depends on the leaf-scale compensation point. A small part of them, especially the hydrophobic ones, can be absorbed directly by the cuticle or diffusing into the leaf through the cuticle (Niinemets et al., 2014). However, in contrast to our understanding of BVOC emissions, understanding the role, magnitude, and mechanisms of dry deposition of BVOCs is still quite poor due to limited measurement techniques, although the dry deposition may play a significant role in estimating BVOC fluxes (Goldstein and Galbally, 2007; Hallquist et al., 2009). Recently, more studies have focused on this topic. Karl et al. (2010) observed substantial dry deposition removal of several OVOCs in field measurements. Bamberger et al. (2011) observed the deposition fluxes of monoterpenes, sesquiterpenes, and oxygenated terpenes over a temperate mountain grassland in an alpine valley after a hailstorm. Park et al. (2013) directly observed bidirectional fluxes for 494 organic ions and daily mean net deposition for 186 organic ions over an orange grove, and recently Nguyen et al. (2015) observed dominant daytime dry deposition fluxes for small, saturated OVOCs derived from isoprene and monoterpene oxidation during summer. Furthermore, the significance of dry deposition of OVOCs has been revealed by various model systems. For example, a regional simulation over the US during summer 2010 indicated that removal of $60-75 \%$ of the tropospheric SOA burden was achieved by dry and wet deposition of condensible organic vapours, which was more significant than direct SOA scavenging (Hodzic et al., 2014). Knote et al. (2015) also found that the modelled SOA concentrations over the continental US would be about 50\% larger than those observed when not considering dry and wet deposition of semi-volatile organic compounds (SVOCs).

Inside the canopy, the emissions, deposition, and chemical reactions all together result in net upward or downward fluxes of different BVOCs. Compared to measurements, numerical models appear to be the only feasible way to assess individual source and sink terms within the canopy. Several gas dry deposition models have been developed since the widely used deposition model proposed by Wesely (1989). However, only a few models focused on dry deposition processes of BVOCs until recently not only possibly because of a lack of recognition of deposition being a potentially important BVOC sink but also because of limited experimental information to constrain the dry deposition calculations. One of the difficulties is in obtaining Henry's law constants or effective Henry's law constants for various organic compounds. The models GECKO-A (Generator of Explicit Chemistry and Kinetics of Organics in the Atmosphere; Aumont et al., 2005) and GROMHE (GROup contribution Method for Henry's law Estimate; Raventos-Duran et al., 2010) were used to calculate the effective Henry's law constants for organic compounds in Hodzic et al. (2014) and Knote et al. (2015). Nguyen et al. (2015) used the Henry's law constants with modifications of the original dry deposition model from Wesely (1989). All of the models used in these studies by Hodzic et al. (2014), Knote et al. (2015), and Nguyen et al. (2015) applied the big-leaf approach (Hicks et al., 1987), which assumed the whole canopy as one single big leaf and thus did not reveal more details on the actual mechanisms inside the canopy that ultimately determine the 
effective BVOC exchange fluxes. The deposition process was also included in several multilayer canopy exchange models for field site studies, e.g. CACHE (Canopy Atmospheric CHemistry Emission model; Bryan et al., 2012), FORCAsT (FORest Canopy Atmosphere Transfer) 1.0 (Ashworth et al., 2015), CAFE (Chemistry of Atmosphere-Forest Exchange) model (Wolfe and Thornton, 2011; Wolfe et al., 2011) and a multilayer exchange model used for global-scale canopy process studies (Ganzeveld et al., 2002, 2010). However, in these studies quite a large number of BVOCs for which deposition can potentially be a relevant sink have been excluded. Moreover, detailed deposition contributions for BVOCs have not been analysed.

In order to fill the gaps mentioned above, a multilayer gas dry deposition model has been developed in this study based on several models in previous studies (Wesely, 1989; Ganzeveld et al., 2002; Nguyen et al., 2015; Zhou et al., 2017). It has been implemented into SOSAA (model to Simulate the concentrations of Organic vapours, Sulphuric Acid and Aerosols; Boy et al., 2011; Zhou et al., 2014) to evaluate emissions, chemistry, dry deposition, and turbulent transport processes for BVOCs within the canopy. The model was applied to study boreal forest BVOC exchange and particularly BVOC deposition for the time period of July 2010 at SMEAR II (Station for Measuring Ecosystem-Atmosphere Relations), also with access to a large number of emission and other complementary measurements collected during an intensive field campaign (HUMPPA, Williams et al., 2011) in July at this site. In this study, we aim to provide a general multilayer parametrization model to calculate the dry deposition velocities of large amounts of gas species included in a detailed chemistry scheme. By using this newly implemented model and conducting an extensive evaluation by comparison with the 2010 field observations, we have investigated individual in-canopy sources and sinks of several featured BVOCs at a boreal forest, and thus give a new insight into how different processes inside the canopy contribute to the BVOC exchange between atmosphere and biosphere.

\section{Measurements}

\subsection{Measurement site}

All the observation data were measured at SMEAR II in Hyytiälä, Finland $\left(61^{\circ} 51^{\prime} \mathrm{N}, 24^{\circ} 17^{\prime} \mathrm{E}, 181 \mathrm{~m}\right.$ a.m.s.l., $\mathrm{UTC}+02)$. The site was situated in a relatively homogeneous boreal forest, mainly composed of Scots pine (Pinus sylvestris), but with some Norway spruce (Picea abies) and broadleaved trees (Bäck et al., 2012). The canopy height $\left(h_{\mathrm{c}}\right)$ was about $18 \mathrm{~m}$ in 2010 . The all-sided leaf area index (LAI) of the canopy was about $7.5 \mathrm{~m}^{2} \mathrm{~m}^{-2}$ with $\sim 6.0 \mathrm{~m}^{2} \mathrm{~m}^{-2}$ overstorey vegetation mainly consisting of tree leaves, $\sim 0.5 \mathrm{~m}^{2} \mathrm{~m}^{-2}$ understorey vegetation consisting of lingonberry (Vaccinium vitis-idaea) and blueberry (Vac- cinium myrtillus), and $\sim 1 \mathrm{~m}^{2} \mathrm{~m}^{-2}$ of cover by mosses on the ground (Launiainen et al., 2013). A more detailed description of this site has been reported in Hari and Kulmala (2005), Haapanala et al. (2007), and Ilvesniemi et al. (2009).

\subsection{Measurement method}

\subsubsection{Meteorological data}

In this study, the measured meteorological data are either used as model input to constrain the simulations in a realistic range or used for analysis. The air temperature $(T)$ was measured using a PT100 sensor at 4.2, 8.4, 16.8, 33.6, 50.4 and $67.2 \mathrm{~m}$ above the ground level. The water vapour mixing ratio was measured using a LI-COR LI-840 infrared light absorption analyser at the same height levels. The relative humidity (RH) was then calculated from the water vapour mixing ratio and the air temperature. The photosynthetically active radiation (PAR, 400-700 nm) was measured at two heights with different instruments: one was measured using a LI-COR LI190SZ quantum sensor at $18 \mathrm{~m}$ and the other was measured using the array of four LI-COR LI-190SZ sensors at $0.6 \mathrm{~m}$. The Reeman MB-1 net radiometer was installed to measure the net radiation $\left(R_{\text {net }}\right)$ at $67 \mathrm{~m}$. The sensible and latent heat (SH and LE) fluxes were measured at $23 \mathrm{~m}$ using a Gill Solent 1012R and LI-COR LI-6262 gas analyzer, and the soil heat flux $\left(G_{\text {soil }}\right)$ was measured using Hukseflux HFP01 heat flux sensors at the ground surface.

\subsubsection{VOC measurement}

The concentrations of 27 different masses (mass-to-charge ratio, $m / z$ ) of BVOCs were measured using the proton transfer reaction quadrupole mass spectrometer (PTR-MS, manufactured by Ionicon Analytik GmbH, Innsbruck, Austria) at the same six height levels as the air temperature (Rantala et al., 2015). The fluxes of BVOCs, based on 45 min averages of BVOC concentrations, were computed every third hour with the surface layer profile method (Rannik, 1998; Rantala et al., 2014). Then the fluxes were filtered as suggested in Rantala et al. (2015), according to which the data points were removed from the time series when $\zeta$ (Obukhov stability parameter) $<-2, \zeta>1$ or $u_{*}$ (friction velocity at $23 \mathrm{~m})<0.2 \mathrm{~m} \mathrm{~s}^{-1}$. Since only 1 month of data were used for comparison with the model results, we did not disregard the outliers and did not apply the gap filling. Finally, for each compound, one data point was filtered out from 164 measurement data points due to $\zeta>1$.

Out of 27 measured masses, 7 single or group compounds were identified and used in this study, which were monoterpenes $(m / z 137)$, isoprene $(m / z 69)$, 2-methyl-3-buten-2ol (MBO, $\left.\mathrm{C}_{5} \mathrm{H}_{10} \mathrm{O}, m / z 87\right)$, methanol $(\mathrm{m} / z 33)$, acetaldehyde $(m / z 45)$, acetone $(m / z 59)$, and formaldehyde (HCHO, $m / z 31)$. MBO fragmented heavily on $m / z 69$; thus, its concentrations were not calibrated. Therefore, the $m / z 69$ was 
not only related to isoprene but also to the fragments of MBO (Rantala et al., 2015). Hence, in this study isoprene and $\mathrm{MBO}$ are analysed together as one group, written as isoprene + MBO. It should also be noted that there is a large uncertainty in the formaldehyde flux measurements according to Rantala et al. (2015). This is mostly due to the high sensitivity of formaldehyde to water vapour, as their proton affinities are close, but also because the concentrations of formaldehyde were not calibrated.

\section{Model description}

\subsection{SOSAA}

SOSAA is a one-dimensional (1-D) column model that was first developed by Boy et al. (2011) and has been applied in several subsequent studies since then (e.g. Kurtén et al., 2011; Mogensen et al., 2011, 2015; Bäck et al., 2012; Boy et al., 2013; Smolander et al., 2014; Zhou et al., 2015, 2017). SOSAA is written in Fortran90 and able to run in parallel in superclusters. The current version has coupled five modules. The meteorology module is derived from SCADIS (scalar distribution; Sogachev et al., 2002), which is originally a three-dimensional (3-D) boundary layer meteorology model. The BVOC emissions from the forest ecosystem are computed using a modified version of MEGAN 2.04 (Model of Emissions of Gases and Aerosols from Nature; Guenther et al., 2006), which was described in detail in Mogensen et al. (2015) and Zhou et al. (2017). The chemistry module codes are created by KPP (kinetic preprocessor; Damian et al., 2002) based on the chemical mechanisms generated by MCMv3.2 (Master Chemical Mechanism version 3.2; http://mcm.leeds.ac.uk/MCM) (Jenkin et al., 1997, 2012; Saunders et al., 2003). The MCM names (if available) of all the species mentioned in this study are listed in Table 1 , which also shows the abbreviation names used in this study (context names), the chemical names, and the formulas. The aerosol module is based on UHMA (University of Helsinki Multicomponent Aerosol model; Korhonen et al., 2004), which describes the nucleation, condensation, coagulation, and deposition of aerosol particles. The gaseous dry deposition module was first introduced in Zhou et al. (2017), mostly focusing on $\mathrm{O}_{3}$ dry deposition. In this study it is extended for all modelled gaseous compounds.

\subsection{Gas dry deposition model}

\subsubsection{Basic equations}

The local change of the trace gas concentration at each model layer is determined by the gas emission $\left(Q_{\text {emis }}\right)$, chemical production and loss $\left(Q_{\text {chem }}\right)$, gas dry deposition $\left(Q_{\text {depo }}\right)$, and turbulent transport flowing into or out of this layer $\left(Q_{\text {turb }}\right)$. Here it should be noted that the positive (negative) $Q_{\text {turb }}$ is a gas source (sink) term, which indicates that the net effect of transportation increases (decreases) the gas concentration within the local layer. All of these processes are included in a mass conservation equation and are computed independently in the model:

$$
\begin{aligned}
\frac{\partial[X]}{\partial t} & =Q_{\mathrm{emis}}^{t}+Q_{\mathrm{chem}}^{t}+Q_{\mathrm{depo}}^{t}+Q_{\mathrm{turb}}^{t} \\
Q_{\mathrm{depo}}^{t} & =-[X]\left(\mathrm{LAD} \cdot V_{\mathrm{dveg}}+A_{\mathrm{s}} V_{\mathrm{dsoil}}\right) \\
Q_{\mathrm{turb}}^{t} & =\frac{\partial}{\partial z}\left(K \frac{\partial[X]}{\partial z}\right) \\
V_{\mathrm{dveg}} & =V_{\mathrm{dveg}}\left(r_{\mathrm{b}}, r_{\mathrm{stm}}, r_{\mathrm{mes}}, r_{\mathrm{cut}}, r_{\mathrm{ws}}, f_{\mathrm{wet}}\right) \\
V_{\mathrm{dsoil}} & =V_{\mathrm{dsoil}}\left(r_{\mathrm{bs}}, r_{\mathrm{soil}}\right) .
\end{aligned}
$$

Here $Q_{\text {emis }}^{t}$ and $Q_{\text {chem }}^{t}$ are directly calculated from the emission module and chemistry module in SOSAA, respectively. The superscript $t$ represents instantaneous quantity. $[X]\left(\mathrm{ng} \mathrm{m}^{-3}\right)$ is the concentration of gas species $X$. LAD $\left(\mathrm{m}^{2} \mathrm{~m}^{-3}\right)$ is the all-sided leaf area density. $A_{\mathrm{s}}\left(\mathrm{m}^{2} \mathrm{~m}^{-3}\right)$ represents the soil area index (see Eq. 17 in Zhou et al., 2017). $K\left(\mathrm{~m}^{2} \mathrm{~s}^{-1}\right)$ is the turbulent diffusivity for scalars. $V_{\text {dveg }}$ $\left(\mathrm{m} \mathrm{s}^{-1}\right)$ is the vegetation-layer-specific conductance, which is a function of $r_{\mathrm{b}}$ (quasi-laminar boundary layer resistance; $\mathrm{s} \mathrm{m}^{-1}$ ), $r_{\mathrm{stm}}$ (stomatal resistance; $\mathrm{s} \mathrm{m}^{-1}$ ), $r_{\text {mes }}$ (mesophyllic resistance; $\left.\mathrm{s} \mathrm{m}^{-1}\right), r_{\text {cut }}$ (dry cuticular resistance; $\left.\mathrm{s} \mathrm{m}^{-1}\right), r_{\mathrm{ws}}$ (resistance to leaf wet skin; $\mathrm{s} \mathrm{m}^{-1}$ ), and $f_{\text {wet }}$ (fraction of wet skin on leaf surface; dimensionless) (see Eqs. 8, 10-13 in Zhou et al., 2017). $V_{\text {dsoil }}$ is the soil conductance, which is a function of $r_{\mathrm{bs}}$ (soil boundary layer resistance; $\mathrm{s} \mathrm{m}^{-1}$ ) and $r_{\text {soil }}$ (soil resistance; $\mathrm{s} \mathrm{m}^{-1}$ ) (see Eq. 9 in Zhou et al., 2017).

$r_{\mathrm{b}}$ and $r_{\mathrm{bs}}$ are related to both the micrometeorological quantities and gas properties. For gas $X, r_{\mathrm{b}}$ is computed assuming forced convection in the quasi-laminar boundary layer above leaf surface (Grace et al., 1980; Meyers, 1987):

$r_{\mathrm{b}}=\frac{S c^{2 / 3}}{0.66 v^{1 / 2}} \sqrt{\frac{l_{d}}{U}}$
$S c=\frac{v}{D_{X}}$
$D_{X}=D_{\mathrm{H}_{2} \mathrm{O}} \sqrt{\frac{M_{\mathrm{H}_{2} \mathrm{O}}}{M_{X}}}$,

where $S c$ (dimensionless) is the Schmidt number for gas $X$ defined as the ratio of kinematic viscosity for air $(v=1.59 \times$ $\left.10^{-5} \mathrm{~m}^{2} \mathrm{~s}^{-1}\right)$ and molecular diffusivity $\left(D_{X} ; \mathrm{m}^{2} \mathrm{~s}^{-1}\right) . D_{X}$ is then estimated with respect to $D_{\mathrm{H}_{2} \mathrm{O}}\left(2.4 \times 10^{-5} \mathrm{~m}^{2} \mathrm{~s}^{-1}\right)$ according to Graham's law using the molar mass $\left(\mathrm{g} \mathrm{mol}^{-1}\right)$ ratio between water vapour $\left(M_{\mathrm{H}_{2} \mathrm{O}}\right)$ and $X\left(M_{X}\right) \cdot l_{d}(0.07 \mathrm{~m})$ is the characteristic length scale of a leaf along the free-stream wind. $U\left(\mathrm{~m} \mathrm{~s}^{-1}\right)$ is the horizontal wind speed above the sublayer of leaf surface. $r_{\mathrm{bs}}$ is calculated as (Nemitz et al., 2000; Launiainen et al., 2013)

$r_{\mathrm{bs}}=\frac{S c-\ln \left(\delta_{0} / z_{*}\right)}{\kappa u_{* g}}$ 
Table 1. A list of the chemical compounds or groups mentioned in this study, with their context names (abbreviation names used in the text), chemical names, MCM names, formulas, and remarks.

\begin{tabular}{|c|c|c|c|c|}
\hline Context name & Chemical name & MCM name & Formula & Remark \\
\hline $\mathrm{O}\left({ }^{1} \mathrm{D}\right)$ & $\begin{array}{l}\text { Excited state } \\
\text { atomic oxygen }\end{array}$ & O1D & $\mathrm{O}\left({ }^{1} \mathrm{D}\right)$ & \\
\hline $\mathrm{O}\left({ }^{3} \mathrm{P}\right)$ & $\begin{array}{l}\text { Ground state } \\
\text { atomic oxygen }\end{array}$ & $\mathrm{O}$ & $\mathrm{O}\left({ }^{3} \mathrm{P}\right)$ & \\
\hline $\mathrm{SO}_{2}$ & Sulfur dioxide & $\mathrm{SO} 2$ & $\mathrm{SO}_{2}$ & \\
\hline $\mathrm{O}_{3}$ & Ozone & $\mathrm{O} 3$ & $\mathrm{O}_{3}$ & \\
\hline $\mathrm{NO}_{2}$ & Nitrogen dioxide & $\mathrm{NO} 2$ & $\mathrm{NO}_{2}$ & \\
\hline $\mathrm{NO}$ & Nitric oxide & NO & $\mathrm{NO}$ & \\
\hline $\mathrm{NH}_{3}$ & Ammonia & $\mathrm{NH} 3$ & $\mathrm{NH}_{3}$ & \\
\hline HONO & Nitrous acid & HONO & HONO & \\
\hline $\mathrm{HNO}_{3}$ & Nitric acid & HNO3 & $\mathrm{HNO}_{3}$ & \\
\hline $\mathrm{OH}$ & Hydroxyl radical & $\mathrm{OH}$ & $\mathrm{HO}$ & \\
\hline $\mathrm{HO}_{2}$ & $\begin{array}{l}\text { Hydroperoxyl radi- } \\
\text { cal }\end{array}$ & $\mathrm{HO} 2$ & $\mathrm{HO}_{2}$ & \\
\hline $\mathrm{H}_{2} \mathrm{O}_{2}$ & Hydrogen peroxide & $\mathrm{H} 2 \mathrm{O} 2$ & $\mathrm{H}_{2} \mathrm{O}_{2}$ & \\
\hline PAN & $\begin{array}{l}\text { Peroxyacetyl } \\
\text { nitrate }\end{array}$ & PAN & $\mathrm{CH}_{3} \mathrm{C}(\mathrm{O}) \mathrm{OONO}_{2}$ & \\
\hline Peracetic acid & Peracetic acid & $\mathrm{CH} 3 \mathrm{CO} 3 \mathrm{H}$ & $\mathrm{CH}_{3} \mathrm{CO}_{3} \mathrm{H}$ & \\
\hline Glyoxal & Glyoxal & GLYOX & $\mathrm{OHCCHO}$ & \\
\hline Methylglyoxal & Methylglyoxal & MGLYOX & $\mathrm{CH}_{3} \mathrm{C}(\mathrm{O}) \mathrm{CHO}$ & \\
\hline Glycolaldehyde & Glycolaldehyde & $\mathrm{HOCH} 2 \mathrm{CHO}$ & $\mathrm{HOCH}_{2} \mathrm{CHO}$ & \\
\hline $\begin{array}{l}\text { 2-Hydroxy-3- } \\
\text { methylbut-3-enal }\end{array}$ & $\begin{array}{l}\text { 2-Hydroxy-3- } \\
\text { methylbut-3-enal }\end{array}$ & $\mathrm{HC} 4 \mathrm{CHO}$ & $\mathrm{CH}_{3} \mathrm{C}\left(\mathrm{CH}_{2}\right) \mathrm{CH}(\mathrm{CHO}) \mathrm{OH}$ & \\
\hline MVK & $\begin{array}{l}\text { Methyl vinyl ke- } \\
\text { tone }\end{array}$ & MVK & $\mathrm{CH}_{3} \mathrm{C}(\mathrm{O}) \mathrm{CH}=\mathrm{CH}_{2}$ & \\
\hline MACR & Methacrolein & MACR & $\mathrm{CH}_{3} \mathrm{C}\left(\mathrm{CH}_{2}\right) \mathrm{CHO}$ & \\
\hline $\mathrm{ROOH}$ & $\mathrm{n} / \mathrm{a}$ & $\mathrm{n} / \mathrm{a}$ & $\mathrm{n} / \mathrm{a}$ & Organic hydrogen peroxides \\
\hline Isoprene & Isoprene & $\mathrm{C} 5 \mathrm{H} 8$ & $\mathrm{C}_{5} \mathrm{H}_{8}$ & \\
\hline Monoterpenes & Monoterpenes & $\mathrm{n} / \mathrm{a}$ & $\mathrm{C}_{10} \mathrm{H}_{16}$ & $\begin{array}{l}\text { A class of terpenes, including } \alpha \text { - } \\
\text { pinene, } \Delta^{3} \text {-carene, } \beta \text {-pinene, etc. }\end{array}$ \\
\hline$\alpha$-Pinene & $\alpha$-Pinene & APINENE & $\mathrm{C}_{10} \mathrm{H}_{16}$ & \\
\hline$\beta$-Pinene & $\beta$-Pinene & BPINENE & $\mathrm{C}_{10} \mathrm{H}_{16}$ & \\
\hline$\Delta^{3}$-Carene & $\Delta^{3}$-Carene & $\mathrm{n} / \mathrm{a}$ & $\mathrm{C}_{10} \mathrm{H}_{16}$ & \\
\hline Myrcene & Myrcene & $\mathrm{n} / \mathrm{a}$ & $\mathrm{C}_{10} \mathrm{H}_{16}$ & \\
\hline Sabinene & Sabinene & $\mathrm{n} / \mathrm{a}$ & $\mathrm{C}_{10} \mathrm{H}_{16}$ & \\
\hline Ocimene & Ocimene & $\mathrm{n} / \mathrm{a}$ & $\mathrm{C}_{10} \mathrm{H}_{16}$ & \\
\hline Limonene & Limonene & LIMONENE & $\mathrm{C}_{10} \mathrm{H}_{16}$ & \\
\hline 1,8-Cineole & 1,8-Cineole & $\mathrm{n} / \mathrm{a}$ & $\mathrm{C}_{10} \mathrm{H}_{18} \mathrm{O}$ & \\
\hline OMT & $\mathrm{n} / \mathrm{a}$ & $\mathrm{n} / \mathrm{a}$ & $\mathrm{C}_{10} \mathrm{H}_{16}$ & Other minor monoterpenes \\
\hline Sesquiterpenes & Sesquiterpenes & $\mathrm{n} / \mathrm{a}$ & $\mathrm{C}_{15} \mathrm{H}_{24}$ & $\begin{array}{l}\text { A class of terpenes, including } \beta \text { - } \\
\text { caryophyllene, farnesene, etc. }\end{array}$ \\
\hline$\beta$-Caryophyllene & $\beta$-Caryophyllene & BCARY & $\mathrm{C}_{15} \mathrm{H}_{24}$ & \\
\hline Farnesene & Farnesene & $\mathrm{n} / \mathrm{a}$ & $\mathrm{C}_{15} \mathrm{H}_{24}$ & \\
\hline OSQ & $\mathrm{n} / \mathrm{a}$ & $\mathrm{n} / \mathrm{a}$ & $\mathrm{C}_{15} \mathrm{H}_{24}$ & Other minor sesquiterpenes \\
\hline $\mathrm{MBO}$ & $\begin{array}{l}\text { 2-Methyl-3-buten- } \\
\text { 2-ol }\end{array}$ & $\mathrm{MBO}$ & $\mathrm{C}_{5} \mathrm{H}_{10} \mathrm{O}$ & \\
\hline Methanol & Methanol & $\mathrm{CH} 3 \mathrm{OH}$ & $\mathrm{CH}_{3} \mathrm{OH}$ & \\
\hline Ethanol & Ethanol & $\mathrm{C} 2 \mathrm{H} 5 \mathrm{OH}$ & $\mathrm{CH}_{3} \mathrm{CH}_{2} \mathrm{OH}$ & \\
\hline Formaldehyde & Formaldehyde & $\mathrm{HCHO}$ & $\mathrm{HCHO}$ & \\
\hline Acetaldehyde & Acetaldehyde & $\mathrm{CH} 3 \mathrm{CHO}$ & $\mathrm{CH}_{3} \mathrm{CHO}$ & \\
\hline Acetone & Acetone & $\mathrm{CH} 3 \mathrm{COCH} 3$ & $\mathrm{CH}_{3} \mathrm{COCH}_{3}$ & \\
\hline Acetol & $\begin{array}{l}\text { Acetol, hydroxy- } \\
\text { acetone }\end{array}$ & ACETOL & $\mathrm{CH}_{2} \mathrm{OHC}(\mathrm{O}) \mathrm{CH}_{3}$ & \\
\hline Pinic acid & Pinic acid & PINIC & $\mathrm{C}_{9} \mathrm{H}_{14} \mathrm{O}_{4}$ & Oxidation product of $\alpha$-pinene \\
\hline BCSOZOH & $\mathrm{n} / \mathrm{a}$ & $\mathrm{BCSOZOH}$ & $\mathrm{C}_{15} \mathrm{H}_{26} \mathrm{O}_{5}$ & $\begin{array}{l}\text { Oxidation product of } \\
\beta \text {-caryophyllene }\end{array}$ \\
\hline ISOP34NO3 & $\mathrm{n} / \mathrm{a}$ & ISOP34NO3 & $\mathrm{C}_{5} \mathrm{H}_{9} \mathrm{ONO}_{3}$ & Oxidation product of isoprene \\
\hline ISOP34OOH & $\mathrm{n} / \mathrm{a}$ & ISOP34OOH & $\mathrm{C}_{5} \mathrm{H}_{10} \mathrm{O}_{3}$ & Oxidation product of isoprene \\
\hline
\end{tabular}


$\delta_{0}=\frac{D_{X}}{\kappa u_{* g}}$,

where $\delta_{0}(\mathrm{~m})$ is the height above ground at which turbulent eddy diffusivity and molecular diffusivity are equal to each other. $z_{*}(0.1 \mathrm{~m})$ is the height up to which the logarithmic wind profile is assumed. $\kappa(0.41)$ is the von Kármán constant and $u_{* g}\left(\mathrm{~m} \mathrm{~s}^{-1}\right)$ is the friction velocity at the ground surface.

In order to obtain other resistances to vegetation and soil surfaces for all the compounds in the chemistry scheme, a modified parameterization method derived from Wesely (1989) and Nguyen et al. (2015) is applied. Hence,

$r_{\mathrm{stm}}=\frac{D_{\mathrm{H}_{2} \mathrm{O}}}{D_{X}} r_{\mathrm{stm}, \mathrm{H}_{2} \mathrm{O}}$

$r_{\text {mes }}=\left(\frac{H}{50 R T_{1}}+100 f_{0}\right)^{-1}$

$r_{\text {cut }}=\left(\frac{10^{-4} H}{R T_{1}}+f_{0}\right)^{-1} r_{\text {cut }, \mathrm{O}_{3}}$

$r_{\mathrm{ws}}=\left(\frac{1}{3 r_{\mathrm{ws}, \mathrm{SO}_{2}}}+\frac{10^{-6} H}{R T_{1}}+\frac{f_{0}}{r_{\mathrm{ws}, \mathrm{O}_{3}}}\right)^{-1}$

$r_{\text {soil }}=\left(\frac{10^{-4} H}{R T_{1} r_{\mathrm{soil}, \mathrm{SO}_{2}}}+\frac{f_{0}}{r_{\mathrm{soil}, \mathrm{O}_{3}}}\right)^{-1}$.

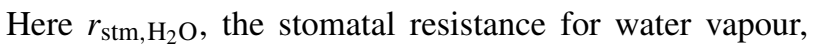
is obtained from the SCADIS module in SOSAA (Zhou et al., 2017). $r_{\mathrm{cut}, \mathrm{O}_{3}}\left(10^{5} \mathrm{~s} \mathrm{~m}^{-1}\right), r_{\mathrm{ws}, \mathrm{SO}_{2}}\left(100 \mathrm{~s} \mathrm{~m}^{-1}\right), r_{\mathrm{ws}, \mathrm{O}_{3}}$ $\left(2000 \mathrm{~s} \mathrm{~m}^{-1}\right), r_{\mathrm{soil}, \mathrm{SO}_{2}}\left(250 \mathrm{~s} \mathrm{~m}^{-1}\right)$, and $r_{\mathrm{soil}, \mathrm{O}_{3}}\left(400 \mathrm{~s} \mathrm{~m}^{-1}\right)$ are constant values as reference resistances for other gases. Here the subscripts $\mathrm{O}_{3}$ and $\mathrm{SO}_{2}$ represent the corresponding resistances of $\mathrm{O}_{3}$ and $\mathrm{SO}_{2}$, respectively. Their values are obtained from Ganzeveld and Lelieveld (1995) and Ganzeveld et al. (1998). $H$ is the Henry's law constant with the unit of $\mathrm{M} \mathrm{atm}^{-1}$. $f_{0}$ (dimensionless) is the reactivity factor with three values, $0,0.1$, and 1 , implying nonreactive, slightly reactive, and reactive gases, respectively. $R$ $\left(0.082 \mathrm{~atm} \mathrm{M}^{-1} \mathrm{~K}^{-1}\right)$ is the gas constant. $T_{1}(\mathrm{~K})$ is leaf temperature.

\subsubsection{Henry's law constant $(H)$}

The Henry's law constants of 1963 chemical compounds included in the current chemistry scheme have to be acquired to calculate the resistances in Eqs. (12) to (15). First, a compound is searched in the list collected by Sander (2015) (Sander's list). If it is in the list, the most reliable $H$ value for this compound shown in the list is used. Otherwise, the program HENRYWIN (Hine and Mookerjee, 1975; Meylan and Howard, 1991) in the software EPI Suite v4.11 (US EPA, 2017 ) is applied to obtain the $H$ value. The program contains two methods to infer the $H$ values referred to as the group method and the bond method. The performance of these two methods was tested for 4592 compounds in the Sander's list, which indicated that the group method predicted slightly more accurate $H$ values $\left(R^{2}=0.89\right)$ than the bond method $\left(R^{2}=0.86\right)$. However, the group method is not available for all the compounds. Hence, the $H$ value derived from the group method is used when available. Otherwise, the result from the bond method is used. Finally, the $H$ values of the inorganic compounds nitric acid $\left(\mathrm{HNO}_{3}\right)$ and hydrogen peroxide $\left(\mathrm{H}_{2} \mathrm{O}_{2}\right)$ are set to $10^{14}$ and $5 \times 10^{7} \mathrm{M} \mathrm{atm}^{-1}$ (Table S4 in Nguyen et al., 2015).

\subsubsection{Reactivity factor $\left(f_{0}\right)$}

The reactivity factors of all the compounds are determined mainly according to the values and rules suggested by Wesely (1989), Karl et al. (2010), and Knote et al. (2015) (Table 2). The $f_{0}$ values of sulfur dioxide $\left(\mathrm{SO}_{2}\right), \mathrm{O}_{3}$, nitrogen dioxide $\left(\mathrm{NO}_{2}\right)$, nitric oxide $(\mathrm{NO})$, nitric acid $\left(\mathrm{HNO}_{3}\right)$, hydrogen peroxide $\left(\mathrm{H}_{2} \mathrm{O}_{2}\right)$, ammonia $\left(\mathrm{NH}_{3}\right)$, peroxyacetyl nitrate (PAN, $\mathrm{CH}_{3} \mathrm{C}(\mathrm{O}) \mathrm{OONO}_{2}$ ), and nitrous acid (HONO) are retrieved from Table 2 in Wesely (1989). The updated $f_{0}$ values of formaldehyde, peracetic acid $\left(\mathrm{CH}_{3} \mathrm{CO}_{3} \mathrm{H}\right)$, acetaldehyde, glyoxal (OHCCHO), methylglyoxal $\left(\mathrm{CH}_{3} \mathrm{C}(\mathrm{O}) \mathrm{CHO}\right)$, glycolaldehyde $\left(\mathrm{HOCH}_{2} \mathrm{CHO}\right)$, 2-hydroxy-3-methylbut3-enal $\left(\mathrm{CH}_{3} \mathrm{C}\left(\mathrm{CH}_{2}\right) \mathrm{CH}(\mathrm{CHO}) \mathrm{OH}\right)$, methanol, ethanol $\left(\mathrm{CH}_{3} \mathrm{CH}_{2} \mathrm{OH}\right)$, acetone, acetol $\left(\mathrm{CH}_{2} \mathrm{OHC}(\mathrm{O}) \mathrm{CH}_{3}\right)$, methyl vinyl ketone $\left(\mathrm{MVK}, \mathrm{CH}_{3} \mathrm{C}(\mathrm{O}) \mathrm{CH}=\mathrm{CH}_{2}\right)$, methacrolein (MACR, $\mathrm{CH}_{3} \mathrm{C}\left(\mathrm{CH}_{2}\right) \mathrm{CHO}$ ), and OVOCs with $-\mathrm{OOH}$ functional group (ROOH) are proposed by Karl et al. (2010). In addition, the $f_{0}$ values of $\mathrm{OH}, \mathrm{NO}_{3}, \mathrm{O}\left({ }^{1} \mathrm{D}\right), \mathrm{O}\left({ }^{3} \mathrm{P}\right)$, and $\mathrm{HO}_{2}$ are set according to Table S4 in Ashworth et al. (2015). Knote et al. (2015) found that there was no significant difference in SVOC deposition when $f_{0}$ values were set to $0,0.1$, and 1 . Hence, they set $f_{0}$ to 0 for SVOCs, regarding them as non-reactive. Therefore, in this study, for the compounds other than those mentioned in Wesely (1989), Karl et al. (2010), and Ashworth et al. (2015), their $f_{0}$ values are set to 0 .

\subsection{Model set-up}

\subsubsection{Meteorology}

In order to validate the newly developed gas dry deposition model and then analyse the BVOC exchange processes between the boreal forest canopy and the atmosphere, the model is set up to simulate the time period from 1 to 31 July 2010 (day of year 182 to 212) with the canopy configuration at SMEAR II. The model contains 51 logarithmically distributed layers from $0 \mathrm{~m}$ at soil surface (layer 1 ) to $3000 \mathrm{~m}$ in the free troposphere (layer 51). The understorey vegetation under $\sim 0.3 \mathrm{~m}$ is included in layer 2 and considered as a broadleaved species in the model. Above that the needleleaf part of dominant coniferous trees is included in 
Table 2. Reactivity factors $\left(f_{0}\right)$ of all the compounds included in the simulation and their references.

\begin{tabular}{|c|c|c|}
\hline Context name & $f_{0}$ & Reference \\
\hline $\mathrm{SO}_{2}$ & 0 & Wesely (1989) \\
\hline $\mathrm{O}_{3}$ & 1 & Wesely (1989) \\
\hline $\mathrm{NO}_{2}$ & 0.1 & Wesely (1989) \\
\hline $\mathrm{NO}$ & 0 & Wesely (1989) \\
\hline $\mathrm{HNO}_{3}$ & 0 & Wesely (1989) \\
\hline $\mathrm{H}_{2} \mathrm{O}_{2}$ & 1 & Wesely (1989) \\
\hline $\mathrm{NH}_{3}$ & 0 & Wesely (1989) \\
\hline PAN & 0.1 & Wesely (1989) \\
\hline HONO & 0.1 & Wesely (1989) \\
\hline Formaldehyde & 1 & Karl et al. (2010) \\
\hline Peracetic acid & 1 & Karl et al. (2010) \\
\hline Acetaldehyde & 1 & Karl et al. (2010) \\
\hline Glyoxal & 1 & Karl et al. (2010) \\
\hline Methylglyoxal & 1 & Karl et al. (2010) \\
\hline Glycolaldehyde & 1 & Karl et al. (2010) \\
\hline 2-Hydroxy-3-methylbut-3-enal & 1 & Karl et al. (2010) \\
\hline Methanol & 1 & Karl et al. (2010) \\
\hline Ethanol & 1 & Karl et al. (2010) \\
\hline Acetone & 1 & Karl et al. (2010) \\
\hline Acetol & 1 & Karl et al. (2010) \\
\hline MVK & 1 & Karl et al. (2010) \\
\hline MACR & 1 & Karl et al. (2010) \\
\hline $\mathrm{ROOH}$ & 1 & Karl et al. (2010) \\
\hline $\mathrm{OH}$ & 1 & Ashworth et al. (2015) \\
\hline $\mathrm{NO}_{3}$ & 1 & Ashworth et al. (2015) \\
\hline $\mathrm{O}\left({ }^{1} \mathrm{D}\right)$ & 0 & Ashworth et al. (2015) \\
\hline $\mathrm{O}\left({ }^{3} \mathrm{P}\right)$ & 0 & Ashworth et al. (2015) \\
\hline $\mathrm{HO}_{2}$ & 1 & Ashworth et al. (2015) \\
\hline
\end{tabular}

layers 3 to 19 within the canopy. The running time step is set to $10 \mathrm{~s}$ due to the implicit time integration method used in model calculations, and the output time step is $30 \mathrm{~min}$.

The main meteorological diagnostic variables $u$ (eastward wind), $v$ (northward wind), $T$, and $q_{v}$ (specific humidity) at the upper boundary are constrained by the ERAInterim reanalysis data obtained from the European Centre for Medium-Range Weather Forecasts (ECMWF; Dee et al., 2011). The lower boundary is set to non-slip and the measured soil heat flux at SMEAR II is used in surface energy balance calculations. At the canopy top, the long-wave radiation provided by the ERA-Interim dataset, as well as the measured downward direct and diffuse global radiation at SMEAR II, is used as input. While inside the canopy, three bands of the radiation (long wave, near infrared, and PAR) at each layer are computed using the meteorology module. A linear interpolation is applied on all the input data to match with the model running time step.

\subsubsection{Chemistry}

The chemistry scheme is based on Mogensen et al. (2015). The full MCMv3.2 oxidation paths of methane $\left(\mathrm{CH}_{4}\right)$, isoprene, $\mathrm{MBO}, \alpha$-pinene $\left(\mathrm{C}_{10} \mathrm{H}_{16}\right), \beta$-pinene $\left(\mathrm{C}_{10} \mathrm{H}_{16}\right)$, limonene $\left(\mathrm{C}_{10} \mathrm{H}_{16}\right)$, and $\beta$-caryophyllene $\left(\mathrm{C}_{15} \mathrm{H}_{24}\right)$ are in- cluded with necessary inorganic reactions. For those emitted BVOCs that are not described by MCM, including 1,8-cineole $\left(\mathrm{C}_{10} \mathrm{H}_{18} \mathrm{O}\right), \Delta^{3}$-carene $\left(\mathrm{C}_{10} \mathrm{H}_{16}\right)$, other minor monoterpenes (OMTs), farnesene $\left(\mathrm{C}_{15} \mathrm{H}_{24}\right)$, and other sesquiterpenes (OSQs), their first-order oxidation reactions with $\mathrm{OH}, \mathrm{O}_{3}$, and $\mathrm{NO}_{3}$ are added (Atkinson, 1997). In addition, the updated chemical reactions of stabilized Criegee intermediates (sCIs) are also added (Boy et al., 2013). The condensation sinks of sulfuric acid $\left(\mathrm{H}_{2} \mathrm{SO}_{4}\right)$ and $\mathrm{HNO}_{3}$ are computed according to Kulmala et al. (2001). The measured concentrations of trace gases $\mathrm{NO}, \mathrm{NO}_{2}\left(\mathrm{NO}_{x}-\mathrm{NO}\right), \mathrm{SO}_{2}, \mathrm{CO}$, $\mathrm{CH}_{4}$, hydrogen $\left(\mathrm{H}_{2}\right)$, and $\mathrm{O}_{3}$ are used to constrain the model (Mogensen et al., 2015). The initial concentrations of all the other compounds are 0 .

\subsubsection{Emission}

The emissions of 15 organic compounds ( $\alpha$-pinene, $\beta$-pinene, $\Delta^{3}$-carene, limonene, 1,8-cineole, OMT, $\beta$ caryophyllene, farnesene, OSQ, isoprene, MBO, methanol, acetaldehyde, acetone, formaldehyde) are computed in the current MEGAN module according to the canopy structure described in Sect. 2.1. In this study only the emissions from the Scots pine are considered (Mogensen et al., 2015). The soil moisture is large enough during the whole month so that the activity factor for soil moisture is always equal to 1.0. The standard emission potentials (SEPs) of these $15 \mathrm{com}$ pounds for July 2010 at SMEAR II applied in the model and proposed in previous studies are shown in Table 3. It should be noted here that the SEP values in previous studies were obtained during different time periods, on different measurement scales, and even by different standardized methods (e.g. Lindfors and Laurila, 2000; Tarvainen et al., 2005; Hakola et al., 2006; Rantala et al., 2015). Therefore, the selected optimum monthly mean SEPs are within the range of measured SEPs or represent the measured fluxes. Hence, the SEPs of total monoterpenes are set to $1227.4 \mathrm{ng} \mathrm{g}(\mathrm{dw})^{-1} \mathrm{~h}^{-1}$ in the range of 838 to $1768.2 \mathrm{ngg}(\mathrm{dw})^{-1} \mathrm{~h}^{-1}$ (Lindfors and Laurila, 2000; Tarvainen et al., 2005; Hakola et al., 2006; Rantala et al., 2015). Then the SEPs of individual monoterpenes ( $\alpha$-pinene, $\beta$-pinene, $\Delta^{3}$-carene, limonene, 1,8-cineole, OMT) are obtained from their average emission spectra (Bäck et al., 2012). The SEPs of farnesene, $\beta$-caryophyllene, and OSQ are set to $45.0 \mathrm{ng} \mathrm{g}(\mathrm{dw})^{-1} \mathrm{~h}^{-1}, 196.2 \mathrm{ng} \mathrm{g}(\mathrm{dw})^{-1} \mathrm{~h}^{-1}$ within the range of 127 to $385 \mathrm{ng} \mathrm{g}(\mathrm{dw})^{-1} \mathrm{~h}^{-1}$ (Tarvainen et al., 2005; Hakola et al., 2006), and $4.8 \mathrm{ng} \mathrm{g}(\mathrm{dw})^{-1} \mathrm{~h}^{-1}$, respectively. The SEP of total sesquiterpenes is thus $246.0 \mathrm{ng} \mathrm{g}(\mathrm{dw})^{-1} \mathrm{~h}^{-1}$ within the range of 159 to $477 \mathrm{ng} \mathrm{g}(\mathrm{dw})^{-1} \mathrm{~h}^{-1}$ (Hakola et al., 2006). The SEP of MBO is $41.3 \mathrm{ng} g(\mathrm{dw})^{-1} \mathrm{~h}^{-1}$ lying in the range of 28 to $56 \mathrm{ng} \mathrm{g}(\mathrm{dw})^{-1} \mathrm{~h}^{-1}$ (Tarvainen et al., 2005; Hakola et al., 2006). Since the total SEP of isoprene and MBO is suggested as $445.6 \mathrm{ng} \mathrm{g}(\mathrm{dw})^{-1} \mathrm{~h}^{-1}$ in Rantala et al. (2015), we thus set the SEP of isoprene as $400 \mathrm{ng} g(\mathrm{dw})^{-1} \mathrm{~h}^{-1}$. 

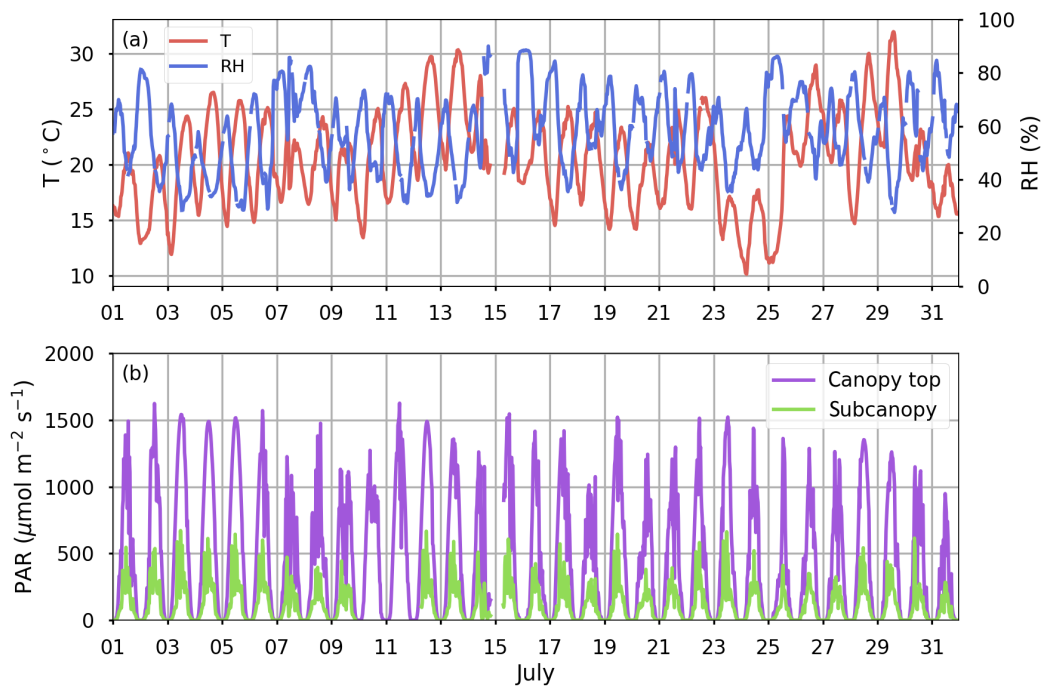

Figure 1. Measured monthly time series of (a) air temperature (red), relative humidity (blue), (b) incoming PAR at canopy top (purple), and PAR at subcanopy (green) in July 2010 at SMEAR II.

The SEP of methanol is set to $75 \mathrm{ng} g(\mathrm{dw})^{-1} \mathrm{~h}^{-1}$ as suggested in Rantala et al. (2015). Therefore, we use the same value $\left(530.5 \mathrm{ng} g(\mathrm{dw})^{-1} \mathrm{~h}^{-1}\right)$ after converting the unit to $\mathrm{ng} g(\mathrm{dw})^{-1} \mathrm{~h}^{-1}$ with a biomass of $509 \mathrm{~g}(\mathrm{dw}) \mathrm{m}^{-2}$. For acetone, Janson and de Serves (2001) proposed a value of $870 \pm 480 \mathrm{ng} g(\mathrm{dw})^{-1} \mathrm{~h}^{-1}$ $\left(1401.7 \pm 773.3 \mathrm{ng} g(\mathrm{dw})^{-1} \mathrm{~h}^{-1}\right)$. Hence, we set the SEP of acetone to $974.1 \mathrm{ng} g(\mathrm{dw})^{-1} \mathrm{~h}^{-1}$, which still lies within the uncertainty range. The SEPs of acetaldehyde and formaldehyde are selected to represent the measured fluxes.

\subsubsection{Selected compounds}

Several representative compounds are selected to analyse the sources and sinks within the canopy for typical BVOCs (Table 4). Monoterpenes, isoprene, MBO, methanol, acetaldehyde, acetone, and formaldehyde are chosen to verify the model by comparing their modelled and measured fluxes above the canopy. These seven compounds along with the sesquiterpenes constitute the majority of the emitted organic gases from the ecosystem at SMEAR II. Acetol is further selected as an additional example of a typical carbonyl compound (in addition to acetaldehyde, methanol, and formaldehyde). Moreover, four increasingly oxidized organic compounds with different carbon chain lengths and chemical functionalities are selected, including ISOP34OOH $\left(\mathrm{C}_{5} \mathrm{H}_{10} \mathrm{O}_{3}\right)$ and ISOP34NO3 $\left(\mathrm{C}_{5} \mathrm{H}_{9} \mathrm{ONO}_{3}\right)$, both of which are oxidation products of isoprene, pinic acid $\left(\mathrm{C}_{9} \mathrm{H}_{14} \mathrm{O}_{4}\right)$ obtained from $\alpha$-pinene oxidation, and BCSO$\mathrm{ZOH}\left(\mathrm{C}_{15} \mathrm{H}_{26} \mathrm{O}_{5}\right)$ produced from $\beta$-caryophyllene oxidation. These compounds were included to be able to simulate the influence of consecutive oxidation and size of the molecule (i.e. changing volatility and Henry's law constant) on the deposition efficiency. They span a range of volatilities and solu- bilities and thereby have different tendencies to deposit onto surfaces.

\section{Results and discussion}

\subsection{Micrometeorology}

During July 2010 at SMEAR II, which was a record warm summer in Finland (Williams et al., 2011), the air temperature varied from 10.1 to $32.0^{\circ} \mathrm{C}$ with a monthly average of $24.5^{\circ} \mathrm{C}$. The $\mathrm{RH}$ showed an opposite diurnal alteration with respect to air temperature with a mean value of $57.5 \%$, ranging from 27.7 to $90.0 \%$ (Fig. 1a). The daytime maximum incoming PAR at the canopy top was larger than $1000 \mu \mathrm{mol} \mathrm{m}{ }^{-2} \mathrm{~s}^{-1}$ during the whole month except 31 July, and even reached over $1500 \mu \mathrm{mol} \mathrm{m}^{-2} \mathrm{~s}^{-1}$ on nine days. In the subcanopy $(0.6 \mathrm{~m})$ the monthly-averaged incoming PAR was only about one-fourth of that at the canopy top, implying apparently slower photochemical reactions happening inside the canopy (Fig. 1b). The accumulated precipitation (liquid water equivalent) of the whole month was $35 \mathrm{~mm}$. Hence, overall the month can be described as sunny and dry, with occasional cloudiness or little precipitation occurring during some of the days.

The simulated and measured July average night and daytime vertical profiles of horizontal wind speed and air temperature as well as diurnal cycles in the friction velocity at $23 \mathrm{~m}$ and in-canopy average $\mathrm{RH}$ are shown in Fig. 2. The wind speed, vertical potential temperature gradient, and friction velocity mainly reflect (and depend on) the vertical mixing conditions inside and above the canopy, which are essential for estimating the overall BVOC exchange inside the canopy. During daytime (sun elevation angle is larger 
Table 3. Standard emission potentials (SEPs) of selected emitted BVOCs. The values used in SOSAA (monthly mean), the corresponding reference values (average \pm standard deviation), and reference literatures are shown. The last column shows how the reference values are standardized, according to PAR, $T$, or both. The unit of SEP is $n g g(d w)^{-1} \mathrm{~h}^{-1}$.

\begin{tabular}{|c|c|c|c|c|}
\hline Context name & SOSAA value & Reference value & Reference and remark & $\begin{array}{l}\text { Standardization } \\
\text { parameters }\end{array}$ \\
\hline \multirow[t]{4}{*}{ Monoterpenes } & 1227.4 & $1500 \pm 0$ & Lindfors and Laurila (2000) & PAR, $T$ \\
\hline & & $1015 \pm 52$ & Tarvainen et al. (2005) & $T$ \\
\hline & & $838 \pm 241,1106 \pm 466$ & Hakola et al. (2006) & $T$ \\
\hline & & $1768.2 \pm 141.5$ & Rantala et al. (2015) & PAR, $T$ \\
\hline$\alpha$-Pinene & 536.4 & $0.437 \cdot \mathrm{SEP}($ monoterpenes $)$ & Bäck et al. (2012) & \\
\hline$\beta$-Pinene & 110.5 & $0.090 \cdot \mathrm{SEP}($ monoterpenes $)$ & Bäck et al. (2012) & \\
\hline$\Delta^{3}$-Carene & 486.1 & $0.396 \cdot \mathrm{SEP}($ monoterpenes $)$ & Bäck et al. (2012) & \\
\hline Limonene & 28.2 & $0.023 \cdot \mathrm{SEP}($ monoterpenes $)$ & Bäck et al. (2012) & \\
\hline 1,8-Cineole & 1.2 & $0.001 \cdot \mathrm{SEP}($ monoterpenes $)$ & Bäck et al. (2012) & \\
\hline OMT & 65.1 & $0.053 \cdot \mathrm{SEP}($ monoterpenes $)$ & Bäck et al. (2012) & \\
\hline Sesquiterpenes & 246.0 & $477 \pm 131,159 \pm 51$ & Hakola et al. (2006) & $T$ \\
\hline Farnesene & 45.0 & & & \\
\hline \multirow[t]{2}{*}{$\beta$-Caryophyllene } & 196.2 & $160 \pm 160$ & Tarvainen et al. (2005) & $T$ \\
\hline & & $127 \pm 35,385 \pm 112$ & Hakola et al. (2006) & $T$ \\
\hline OSQ & 4.8 & & & \\
\hline Isoprene & 400 & $445.6 \pm 28.3$ & $\begin{array}{l}\text { The reference value referred to the } \\
\text { sum of isoprene and MBO (Rantala } \\
\text { et al., 2015). }\end{array}$ & PAR, $T$ \\
\hline \multirow[t]{3}{*}{$\mathrm{MBO}$} & 41.3 & $28 \pm 1$ & Tarvainen et al. (2005) & $T$ \\
\hline & & $28 \pm 7,56 \pm 19$ & Hakola et al. (2006) & PAR, $T$ \\
\hline & & $445.6 \pm 28.3$ & $\begin{array}{l}\text { The reference value referred to the } \\
\text { sum of isoprene and MBO (Rantala } \\
\text { et al., 2015). }\end{array}$ & PAR, $T$ \\
\hline Methanol & 530.5 & $530.5 \pm 35.4$ & Rantala et al. (2015) & $T$ \\
\hline Acetone & 974.1 & $1401.7 \pm 773.3$ & Janson and de Serves (2001) & $T$ \\
\hline Formaldehyde & 530.5 & & & \\
\hline Acetaldehyde & 249.8 & & & \\
\hline
\end{tabular}

than $10^{\circ}$ ), the observed wind speed shows a large decrease from $3.4 \mathrm{~m} \mathrm{~s}^{-1}$ above the canopy to $0.9 \mathrm{~m} \mathrm{~s}^{-1}$ deeper inside the canopy due to canopy drag. The nighttime (sun elevation angle is smaller than $0^{\circ}$ ) profile shows a similar pattern (Fig. 2a). Here we focus on the meteorological conditions below about $2 h_{\mathrm{c}}(36 \mathrm{~m})$, where the air pressure and density can be considered the same as that at the ground level. Hence, the air temperature can be assumed to be the potential temperature within this vertical range (the largest difference between potential temperature and $T$ at $36 \mathrm{~m}$ is about $0.35 \mathrm{~K}$, which is smaller than the observed gradients). The observed vertical profile of temperature shows a negative upward gradient within and above the canopy during daytime, indicating the occurrence of weakly unstable conditions, which facilitate vertical mixing within and above the canopy. In contrast, the positive upward gradient in temperature profile implies an inhibition of turbulence motions during nighttime (Fig. 2b). The horizontal wind speed and the temperature are well simulated by the model (Fig. 2a and b). The measured diurnal cycle of friction velocity at canopy top indicates more production of turbulence at daytime compared to that at night- time due to the buoyancy term (Fig. 2c). The model overestimates the nighttime friction velocity, which may imply not only an excessive mixing between the canopy and overlaying inversion layer for nocturnal BVOC exchange but also a possible misrepresentation of other drivers of BVOC sources and sinks such as moisture conditions, as discussed below. The observed monthly-averaged RH values exceed $70 \%$ from about 02:00 to 06:00 LT, indicating the occurrence of wet skin on the leaf surface (Altimir et al., 2006; Zhou et al., 2017). However, the model underestimates the RH values during night and in the early morning, resulting in simulated RH values generally less than $70 \%$, on average not larger than $60 \%$, during the simulation period (Fig. 2d). Therefore, the observed RH values inside the canopy were used to parametrize $f_{\text {wet }}$ when calculating the deposition velocity to represent a more realistic leaf wetness condition. It should be noted here that although $\mathrm{RH}=70 \%$ is chosen as a threshold of the occurrence of leaf wetness in the model, the leaf wetness may already play a role when $\mathrm{RH}<70 \%$, e.g. due to the deliquescent effect of deposited salt on the vegetation surfaces. 
Table 4. A list of selected featured BVOCs with their Henry's law constants $(H)$, the $H$ method references (SE as from Sander, 2015, MH as manually set, EB as calculated with the bond method using EPI Suite v4.11, EG as calculated with the group method using EPI Suite v4.11), the reactivity factors $\left(f_{0}\right)$, the $f_{0}$ references, and remarks.

\begin{tabular}{llllll}
\hline Context name & $H\left(\mathrm{M} \mathrm{atm}^{-1}\right)$ & $H$ reference & $f_{0}$ & $f_{0}$ reference & Remark \\
\hline$\alpha$-Pinene & $3.0 \times 10^{-2}$ & SE & 0 & Others & \\
$\beta$-Pinene & $1.6 \times 10^{-2}$ & SE & 0 & Others & \\
$\Delta^{3}$-Carene & $1.6 \times 10^{-2}$ & SE & 0 & Others & \\
Myrcene & $8.9 \times 10^{-2}$ & SE & 0 & Others & \\
Sabinene & $1.6 \times 10^{-2}$ & SE & 0 & Others & \\
Ocimene & $3.0 \times 10^{-2}$ & SE & 0 & Others & \\
Limonene & $4.9 \times 10^{-2}$ & SE & 0 & Others & $H=0.5 \cdot[H(\alpha$-pinene $)+$ \\
1,8-Cineole & 6.0 & SE & 0 & Others & \\
OMT & $2.3 \times 10^{-2}$ & MH & 0 & Others & \\
& & & & & \\
Isoprene & $1.3 \times 10^{-2}$ & SE & 0 & Others & \\
MBO & 65 & SE & 0 & Others & $H(\beta$-caryophellene $)$ \\
$\beta$-Caryophyllene & $1.45 \times 10^{-3}$ & EB & 0 & Others & \\
Farnesene & 0.102 & EG & 0 & Others & \\
OSQ & $1.45 \times 10^{-3}$ & MH & 0 & Others & \\
Formaldehyde & $3.2 \times 10^{3}$ & SE & 1 & Karl et al. (2010) & \\
Methanol & $2.0 \times 10^{2}$ & SE & 1 & Karl et al. (2010) & \\
Acetaldehyde & 13 & SE & 1 & Karl et al. $(2010)$ & \\
Acetone & 28 & SE & 1 & Karl et al. (2010) & \\
Acetol & $7.8 \times 10^{3}$ & SE & 1 & Karl et al. (2010) & \\
Pinic acid & $1.70 \times 10^{9}$ & EG & 0 & Others & \\
BCSOZOH & $9.09 \times 10^{7}$ & EB & 0 & Others & \\
ISOP34NO3 & $5.05 \times 10^{4}$ & EB & 0 & Others & \\
ISOP34OOH & $1.47 \times 10^{6}$ & EB & 1 & Karl et al. (2010) & \\
\hline
\end{tabular}

\subsection{Model validation}

The current version of SOSAA with a similar set-up has been applied and verified in Zhou et al. (2017); hence, here we only show the comparisons of simulated and observed parameters that are relevant for BVOC exchange as presented in this study.

\subsubsection{Energy fluxes}

The simulated and measured monthly-averaged diurnal cycles of energy fluxes for the canopy-soil ecosystem are compared in order to verify the modelled micrometeorology with a focus on the radiation and energy balance (Fig. 3). During daytime, e.g. at 12:30 LT, the measured downward net radiation $\left(-414 \mathrm{~W} \mathrm{~m}^{-2}\right)$ is approximately balanced by $\mathrm{SH}$ flux $\left(200 \mathrm{~W} \mathrm{~m}^{-2}\right)$, LE flux $\left(190 \mathrm{~W} \mathrm{~m}^{-2}\right)$, and a small soil heat flux $\left(25 \mathrm{~W} \mathrm{~m}^{-2}\right)$ into the soil. During nighttime, e.g. at 01:30 LT, the net upward long-wave radiation $\left(44 \mathrm{~W} \mathrm{~m}^{-2}\right)$ along with minor LE flux $\left(4 \mathrm{~W} \mathrm{~m}^{-2}\right)$ is partly compensated for by a downward SH flux $\left(-27 \mathrm{~W} \mathrm{~m}^{-2}\right)$, resulting in an overall nocturnal decrease in the canopy temperature and onset of a stable inversion at the canopy top.
Although the model underestimates the monthly-averaged diurnal SH flux from 11:00 to 20:00 LT by a maximum of $76 \mathrm{~W} \mathrm{~m}^{-2}$, the simulation results of energy fluxes show an acceptable agreement with the measurements. Moreover, the promising agreement between modelled and measured LE flux indicates a realistic representation of the water vapour exchange between the air and the ecosystem, which hints at a realistic representation of stomatal resistance essential for the representation of stomatal removal of the chemical compounds in the model.

\subsubsection{BVOC fluxes}

The BVOC emissions in SOSAA are simulated using MEGAN with prescribed standard emission potentials. The modelled emissions of monoterpenes were evaluated by Smolander et al. (2014) via comparisons between simulated and measured fluxes and concentrations for June 2007 at SMEAR II. In this study, the simulated fluxes at the canopy top for six different emitted compounds or groups (including monoterpenes, isoprene $+\mathrm{MBO}$, methanol, acetaldehyde, acetone, formaldehyde) are compared with the measurements. 


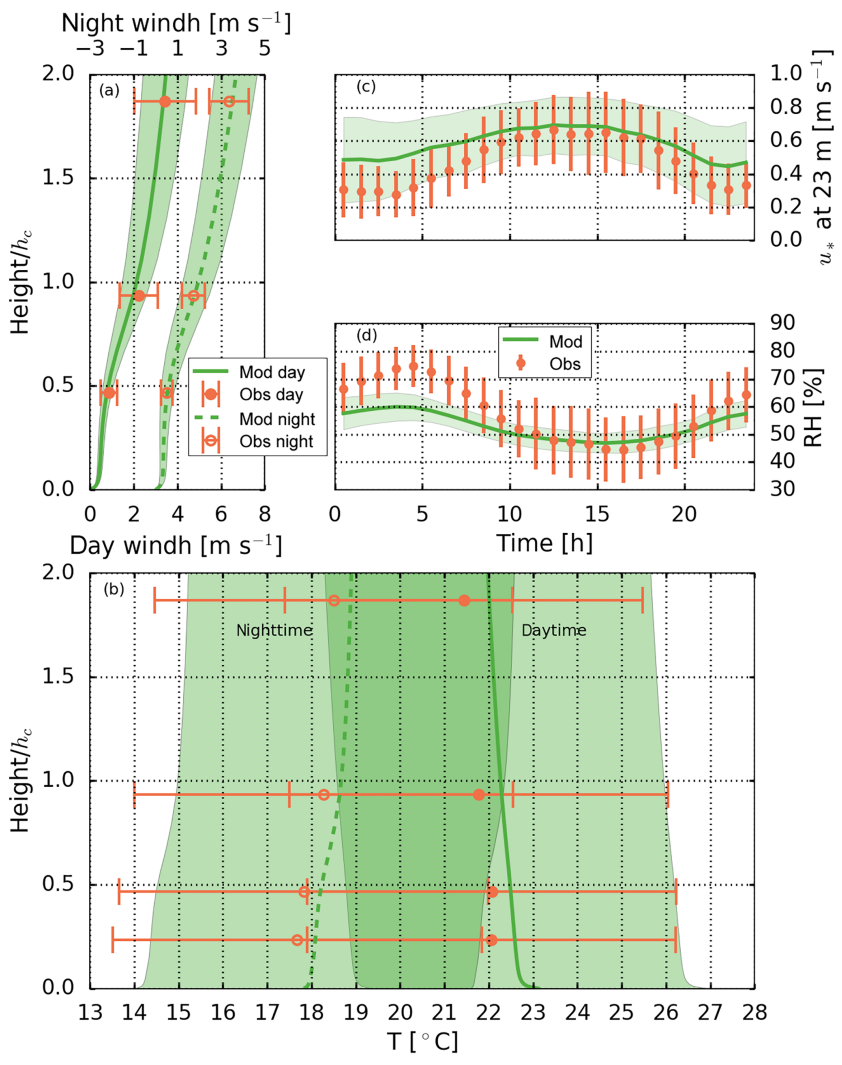

Figure 2. Modelled (green solid line for daytime, green dashed line for nighttime) and measured (yellow solid circle for daytime, yellow empty circle for nighttime) profiles of (a) horizontal wind speed (windh) and (b) air temperature $(T)$. The ranges of \pm 1 SD (standard deviation) of modelled and measured data are marked as shades and error bars. The height is normalized by canopy height $\left(h_{\mathrm{c}}\right)$. The monthly-averaged diurnal cycles of modelled (green line) and measured (yellow dots) (c) friction velocity $\left(u_{*}\right)$ at $23 \mathrm{~m}$ and (d) mean RH inside the canopy are also plotted. The ranges of \pm 1 SD of modelled and measured data are marked as shades and vertical lines.

Figure 4 shows the modelled and measured monthly mean diurnal cycles in BVOC fluxes at the canopy top. The measured fluxes of monoterpenes, isoprene + MBO, methanol, acetaldehyde, and acetone show a similar diurnal pattern mainly following the diurnal patterns of emission intensities (Fig. 4a-e). During daytime, the fluxes of these BVOCs increase continuously and reach a maximum at around 14:00 LT in the afternoon. The observed nighttime upward fluxes of these BVOCs, except monoterpenes whose emissions are strongly regulated by temperature instead of light, are close to zero when both the emission and the turbulence are small. For methanol and acetaldehyde, the measured fluxes can be downward at nighttime and in the early morning due to gas dry deposition showing bidirectional fluxes (Fig. 4c and d). Schallhart et al. (2016) also observed considerable downward flux of methanol from 01:00 to 08:00 LT over a Mediterranean oak-hornbeam forest and proposed that this was due to deposition under the presence of dew. The measured monthly-averaged diurnal flux for formaldehyde is mostly downward and does not show an apparent diurnal pattern. The observed apparent bidirectional formaldehyde fluxes also indicate that, although the deposition may play a significant role in its exchange processes, other effects, e.g. emission and chemical reactions, might provide a comparable contribution to the overall formaldehyde source-sink balance (Fig. 4f).

The diurnal variations in fluxes for monoterpenes, isoprene $+\mathrm{MBO}$, methanol and acetaldehyde are well represented by the model. Although for isoprene $+\mathrm{MBO}$ the monthly-averaged daytime flux is underestimated up to about $0.025 \mu \mathrm{g} \mathrm{m}^{-2} \mathrm{~s}^{-1}(\sim 65.0 \%)$ at 17:30 LT, the values are still in the range of the measurement uncertainties and day-to-day variation (Fig. 4b). For acetone, the model underestimates the upward flux in the morning and shows a dominant downward flux around 04:00 LT, which is not seen in the observations, implying a potential overestimation of the role of deposition or a missing source in canopy exchange of acetone. In contrast, the model overestimates the upward flux from $\sim 10: 00$ to $\sim 16: 00$ LT at daytime probably due to excessive sources (Fig. 4e). The model overestimates the downward flux of formaldehyde in the morning from $\sim$ 04:00 to $\sim$ 12:00 LT and does not capture the observed abrupt increase in this downward flux between 12:00 and 16:00 LT. However, considering the large uncertainties of measurements of formaldehyde flux as mentioned in Sect. 2.2.2, the differences between modelled and observed diurnal variation of formaldehyde flux do not indicate a poor performance regarding the simulations of formaldehyde sources, sinks, and exchange (Fig. 4f). In summary, considering the 3-D nature of the actual observation conditions and the resulting uncertainties introduced in such comparison of a 1-D model results with measurements, there seems to be a good correspondence between simulated and observed diurnal cycles in BVOC exchange fluxes.

\subsection{Overview of in-canopy sources and sinks}

The simulated monthly-averaged relative contributions of individual in-canopy sources and sinks $\left(\bar{Q}_{\mathrm{rel}, n}^{\Delta, h_{\mathrm{c}}}, \mathrm{Eq}\right.$. A7) during the whole day, the daytime, and the nighttime are shown in Fig. 5. Figure 5a shows the monthly-averaged relative contributions by emissions, dry deposition, chemistry, and turbulent transport in the overall concentration changes during the whole day. For those compounds that are emitted from the canopy, emission is always a significant source within the canopy. However, the sink terms are different for individual gases and we can distinguish three contrasting exchange regimes. First, $\sim 86 \%$ of the emitted monoterpenes and $\sim 93 \%$ of isoprene $+\mathrm{MBO}$ is transported out of the canopy. Secondly, for the emitted sesquiterpenes, $\sim 70 \%$ is removed by chemical oxidation within the canopy due to their very high reactivity, and only $\sim 29 \%$ escapes the 


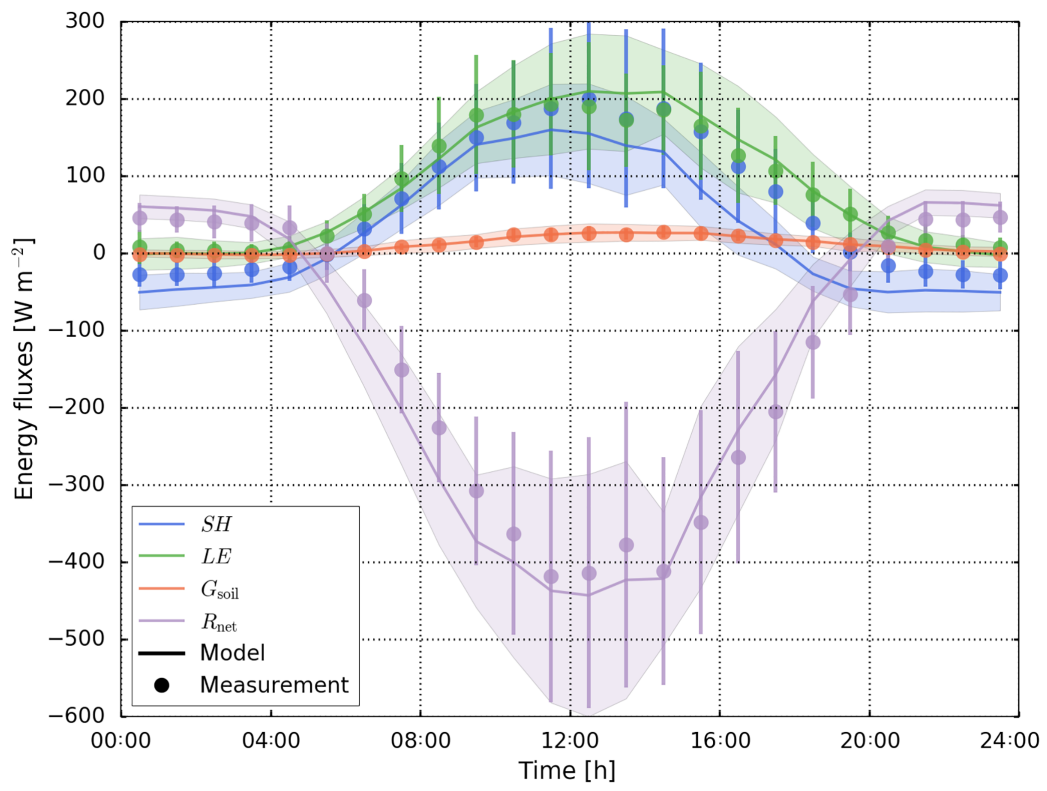

Figure 3. The modelled (solid lines) and measured (points) monthly-averaged diurnal cycles of sensible heat flux (SH, blue), latent heat flux (LE, green), soil heat flux $\left(G_{\text {soil }}\right.$, yellow), and upward net radiation $\left(R_{\text {net }}\right.$, purple; the observed $R_{\text {net }}$ is at $\left.67 \mathrm{~m}\right)$. The ranges of \pm 1 standard deviation for modelled and measured data are marked by shaded areas and vertical lines, respectively.
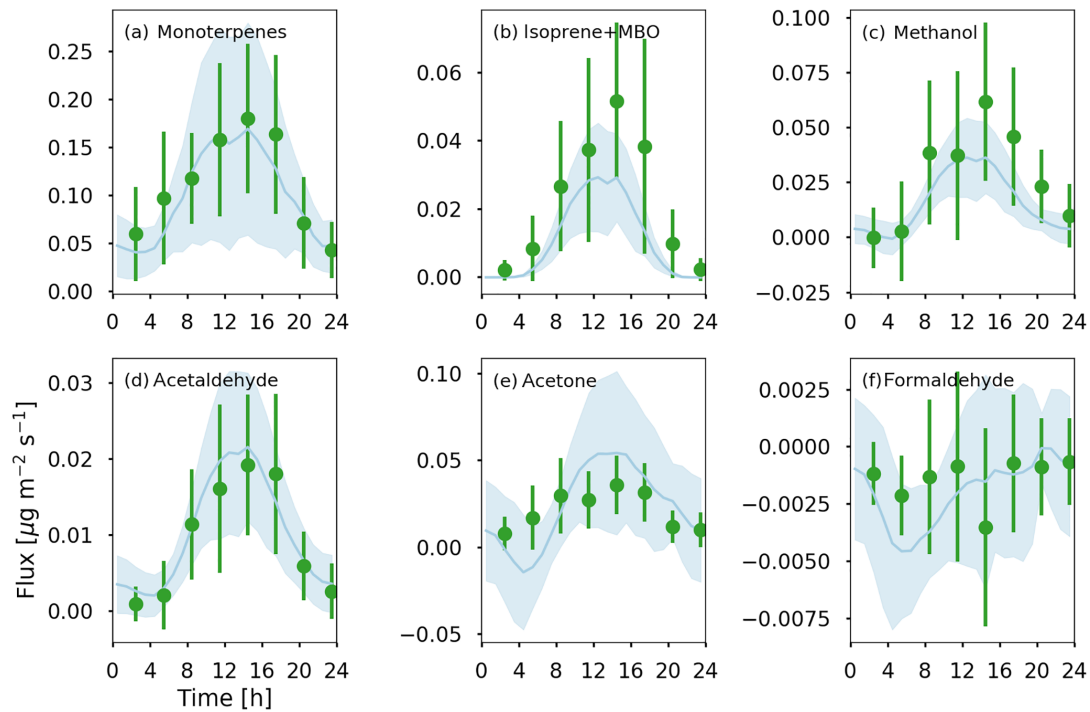

Figure 4. Modelled (blue lines) and measured (green points) monthly-averaged diurnal cycles of fluxes for (a) monoterpenes, (b) isoprene $+\mathrm{MBO}$, (c) methanol, (d) acetaldehyde, (e) acetone, and (f) formaldehyde at the canopy top. The ranges of \pm 1 standard deviation for modelled and measured data are marked by shaded areas and vertical lines, respectively. The $x$ labels and $y$ labels of (d) also apply to all the other panels.

canopy. This result is comparable with the estimation by Rinne et al. (2007), which showed that the fraction of the emitted sesquiterpenes being able to reach the measurement height $(22 \mathrm{~m})$ at the same site was about $30-40 \%$ in July. Rinne et al. (2012) presented a slightly higher ratio between above canopy flux and canopy emission of $\beta$-caryophyllene, which was about $50 \%$ during daytime and below $40 \%$ dur- ing nighttime. Thirdly, dry deposition plays a significant or even dominant role among the removal processes and contributes about $80,35,100$, and $100 \%$ to the total sinks for methanol, acetaldehyde, acetone, and formaldehyde within the canopy, respectively. Hence, their fluxes are bidirectional in the simulation (Fig. 4c-f). The results indicate that a large portion of methanol molecules are deposited inside the 
canopy instead of being transported out of the canopy, which was also noticed by other studies. Karl et al. (2005) found that methanol was deposited mostly in the lower canopy part during daytime and taken up significantly inside the canopy at nighttime in a loblolly pine forest in July 2003. Laffineur et al. (2012) even reported net daily negative methanol fluxes in a temperate mixed forest in summer during 2009 and 2010. At SMEAR II, Rantala et al. (2015) showed that from April to September during 2010 to 2013 the ratio between the cumulative deposition and the cumulative emission was slightly lower than $40 \%$, which is about half of that in this study $(80 \%)$. This discrepancy may result from the soil deposition explicitly calculated in this study, which is about $42 \%$ of the overall dry deposition sink of methanol. In the case of acetone and formaldehyde, the dry deposition sinks exceed the emission sources by about 20 and $>170 \%$, respectively, and the net canopy sink of these compounds is partly compensated for by downward turbulent transport.

During daytime, which lasts about $18 \mathrm{~h}$ in July, the relative contributions by chemistry, deposition, and mixing to the overall concentration changes and fluxes for emitted gases change very little compared to the whole-day average, and the maximum difference of monthly mean $\bar{Q}_{\mathrm{rel}, n}^{\Delta, h_{\mathrm{c}}}$ is less than 0.06 (Fig. 5b). At nighttime, the mass balance patterns for emitted compounds are similar to those in daytime except for isoprene $+\mathrm{MBO}$, which changes dramatically since the emission reduces a lot due to lack of light (Fig. 5c). Consequently, inside the canopy the source is only $\sim 51 \%$ of the sink for isoprene $+\mathrm{MBO}$, which implies an imbalance and thus concentration reduction during nighttime. However, the absolute nighttime concentration change for isoprene + MBO is nearly zero, as we will discuss below in Sect. 4.5.

In general, all the selected non-emitted gases that are chemically produced from the emitted precursor gases are removed by deposition, predominantly showing downward fluxes (Fig. 5a). However, their chemistry contribution to total sources varies in a wide range from $\sim 3 \%$ (acetol) to $\sim 70 \%$ (ISOP34NO3), implying a complicated relationship between the vertical distribution of their precursors, the subsequent oxidation reactions, and their own deposition processes. According to the monthly-average relative contribution of chemistry $\left(\bar{Q}_{\text {rel,chem }}^{\Delta, h_{\mathrm{c}}}\right)$ during the whole day, the nonemitted gases can be divided into two categories, one with $\left|\bar{Q}_{\text {rel,chem }}^{\Delta, h_{\mathrm{c}}}\right|<0.25$ and the other with $\left|\bar{Q}_{\text {rel,chem }}^{\Delta, h_{\mathrm{c}}}\right| \geq 0.25$.

For the first category, the modelled relative contribution by deposition is much larger than the in-canopy chemical production, which is $\sim 3, \sim 11$, and $\sim 18 \%$ of the deposited gases for acetol, pinic acid, and $\mathrm{BCSOZOH}$, respectively. The chemistry contributions of them change less than 0.05 at daytime (Fig. 5b) and less than 0.10 at nighttime (Fig. 5c) compared to the whole-day average. In the second category, the oxidation of isoprene initiated by $\mathrm{OH}$ can produce $\sim 33$ and $\sim 70 \%$ of the lost gases for ISOP34OOH

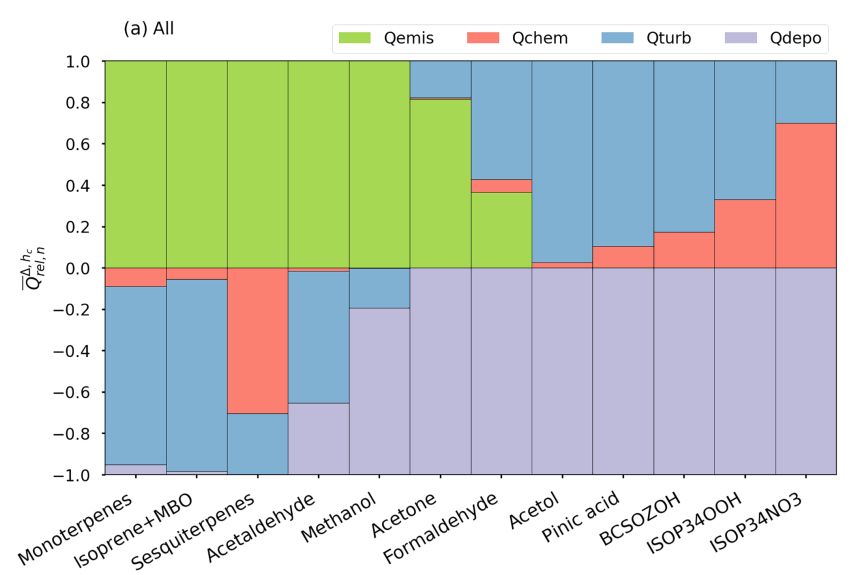

(b) Day

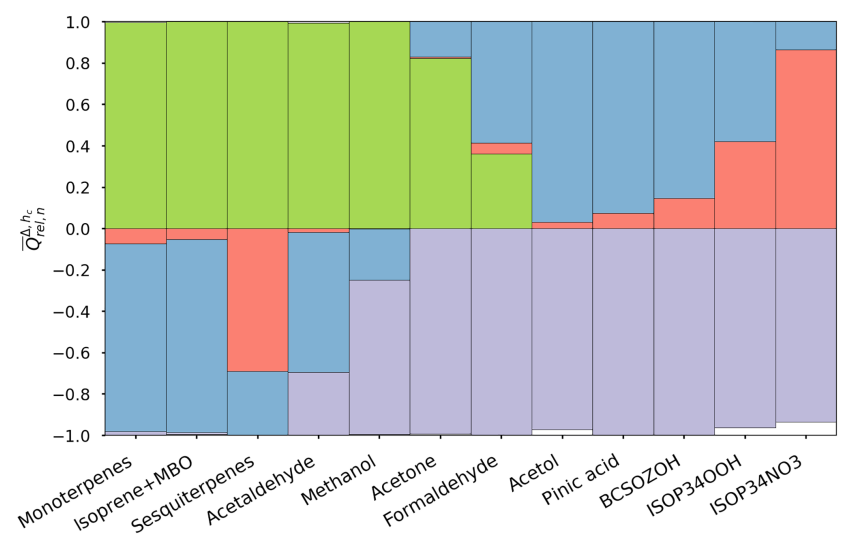

(c) Night

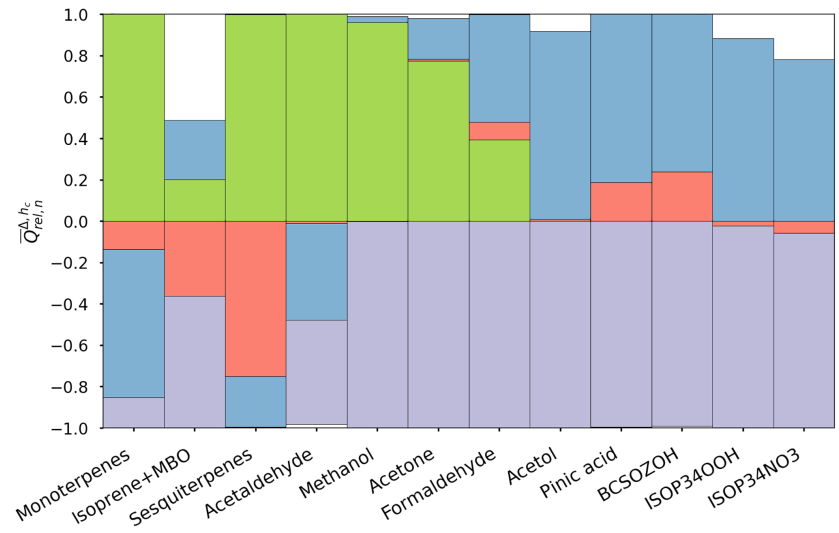

Figure 5. Monthly-averaged relative contributions of in-canopy sources and sinks $\left(\bar{Q}_{\mathrm{rel}, n}^{\Delta, h_{\mathrm{c}}}\right)$, including gas emissions (emis, green), net chemical production and loss (chem, red), turbulent transport (turb, blue), and gas dry deposition (depo, purple) for selected BVOCs during (a) the whole month, (b) daytime, and (c) nighttime.

and ISOP34NO3 inside the canopy (Fig. 5a). In daytime, their relative contributions of chemistry increase to $\sim 0.42$ and $\sim 0.86$ due to a higher concentration of $\mathrm{OH}$ (Fig. $5 \mathrm{~b}$ ). At nighttime, in contrast, they are even destroyed by chemical reactions with $\mathrm{O}_{3}$ given the low $\mathrm{OH}$ concentrations (Fig. 5c). 

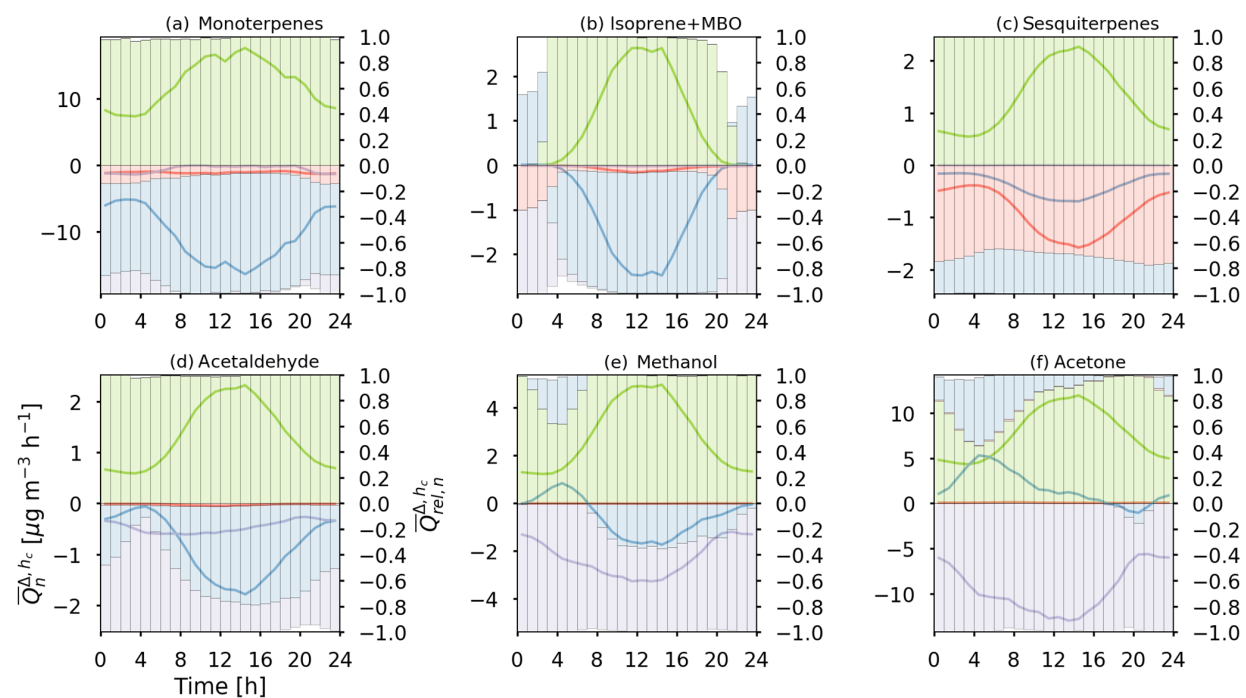

Figure 6. Modelled monthly-averaged diurnal cycle of $\bar{Q}_{n}^{\Delta, h_{\mathrm{c}}}$ (solid lines) and the relative contributions $\bar{Q}_{\text {rel, } n}^{\Delta, h_{\mathrm{c}}}$ (bars) of gas emissions (green), net chemical production and loss (red), turbulent transport (blue), and gas dry deposition (purple) within the canopy for (a) monoterpenes, (b) isoprene $+\mathrm{MBO},(\mathbf{c})$ acetaldehyde, (d) sesquiterpenes, (e) methanol, and (f) acetone. The $x$ labels and $y$ labels of (d) also apply to all the other panels.

\subsection{Classification of BVOCs}

The selected BVOCs are finally classified into five categories: (i) Cemis in which emitted gases are mostly transported out of the canopy (monoterpenes, isoprene + MBO); (ii) Cemis-chem in which emitted gases are removed significantly by chemistry (sesquiterpenes); (iii) Cemis-depo in which emitted gases are removed by a significant deposition contribution (acetaldehyde, methanol, acetone, formaldehyde); (iv) Cdepo in which the gases are mostly deposited (acetol, pinic acid, BCSOZOH); and finally (v) Cchemdepo in which the chemical production can compensate for a significant portion of deposition sink (ISOP34OOH, ISOP34NO3).

This classification also implies that for the gases in categories Cemis-chem and Cemis-depo, it is difficult to determine the actual emission rates only with canopy-top or surface layer flux measurements since the actual emissions can be significantly reduced by chemical reactions and dry deposition processes. For example, the lack of observations on the latter process implies that we rely to a large extent on parametrizations such as the one proposed by Wesely (1989).

The classifications of the featured BVOCs here can also be extended to other canopy types in summertime nearly without any modifications. For example, for isoprene + MBO, monoterpenes, and sesquiterpenes the emission is always the only dominant local source within a canopy, although the emission potentials of these BVOCs can vary 2 or more orders of magnitude between different plant types (Guenther et al., 2012). Therefore, the current classifications for isoprene $+\mathrm{MBO}$, monoterpenes, and sesquiterpenes also apply to other canopy types.
In addition to emission and dry deposition, acetaldehyde, methanol, acetone, and formaldehyde can be chemically produced from the oxidation of other BVOCs and destroyed via OH oxidation or photolysis (Millet et al., 2010; Jacob et al., 2005; Khan et al., 2015; DiGangi et al., 2011). The chemical production and removal cancel out each other, which can finally result in negligible net chemical effect as shown in this study (Fig. 5a). Therefore, the classifications of these four compounds also apply to other canopy types. However, further investigation with numerical simulations is still needed to verify the relative contributions of net chemical effects for different canopy types.

Chemical production is the only source in the planetary boundary layer for the other non-emitted gases, including acetol, pinic acid, BCSOZOH, ISOP34OOH, and ISOP34NO3. They are either produced by direct chemical reactions inside the canopy or transported from above the canopy in all canopy types. Therefore, the classifications of them apply in a general way.

\subsection{Diurnal cycles of in-canopy sources and sinks}

The monthly-averaged diurnal cycles in the source and sink terms $\bar{Q}_{n}^{\Delta, h_{\mathrm{c}}}$ (Eq. A5) and their relative contributions $\left(\bar{Q}_{\mathrm{rel}, n}^{\Delta, h_{\mathrm{c}}}\right)$ for selected BVOCs are shown in Figs. 6 and 7. All of the $\bar{Q}_{\text {emis }}^{\Delta, h_{\mathrm{c}}}$ values of the emitted gases follow the diurnal patterns of the temperature and incoming PAR, which keep minimum values during nighttime and reach a maximum in the afternoon at $\sim 14: 00 \mathrm{LT}$. Among them, the emission of isoprene $+\mathrm{MBO}$ strongly depends on the light compared to other compounds; hence, its $\bar{Q}_{\mathrm{emis}}^{\Delta, h_{\mathrm{c}}}$ is zero at night. 

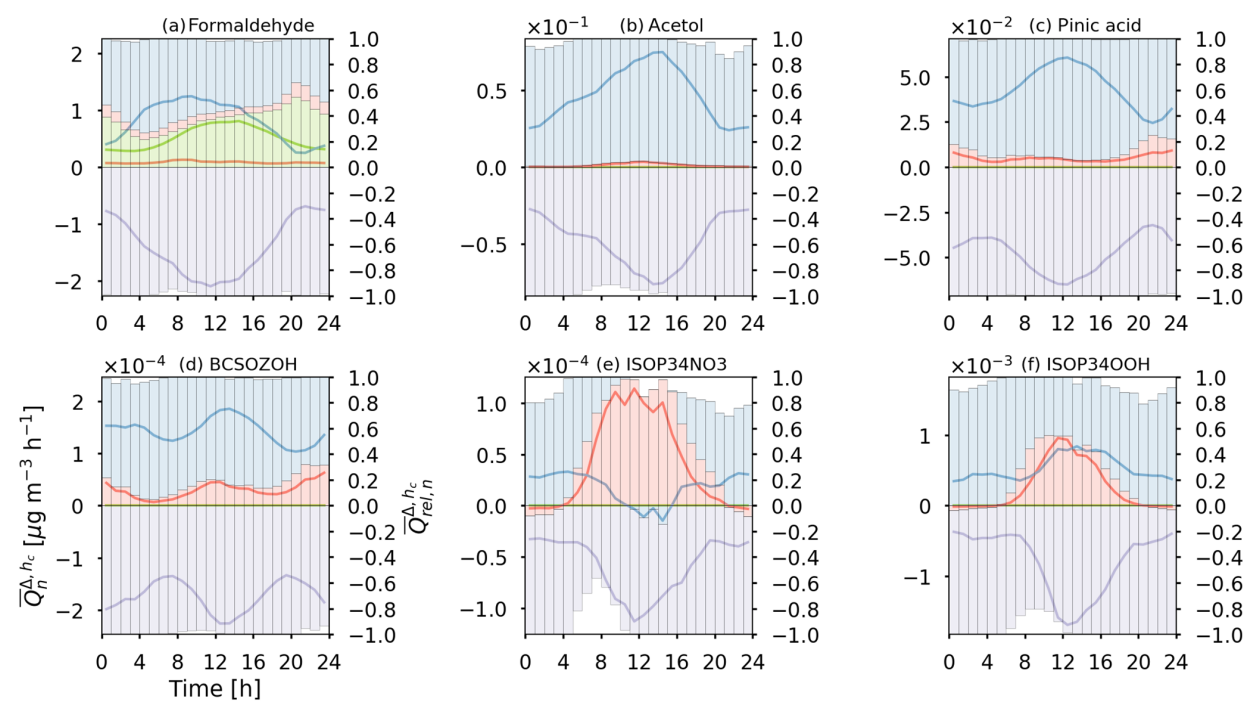

Figure 7. The same as Fig. 6 but for (a) formaldehyde, (b) acetol, (c) pinic acid, (d) BCSOZOH, (e) ISOP34NO3, and (f) ISOP34OOH.

For the category Cemis, the $\bar{Q}_{\text {turb }}^{\Delta, h_{\mathrm{c}}}$ term expressing the role of turbulent transport in concentration tendencies shows an approximately opposite diurnal pattern compared to $\bar{Q}_{\text {emis }}^{\Delta, h_{\mathrm{c}}}$, implying that most of the emitted gases are transported out of the canopy throughout the whole day (Fig. 6a and b). Although the relative contribution of monoterpene emission is about 1.00 during the whole day, the absolute value alters, e.g. the mean nighttime $\bar{Q}_{\text {emis }}^{\Delta, h_{\mathrm{c}}}\left(8.4 \mu \mathrm{g} \mathrm{m}^{-3} \mathrm{~h}^{-1}\right)$ is about $58 \%$ of mean daytime value $\left(14.5 \mu \mathrm{g} \mathrm{m}^{-3} \mathrm{~h}^{-1}\right)$ (Fig. 6a). For isoprene $+\mathrm{MBO}$, there is no nighttime emission of isoprene; hence, the nighttime $\bar{Q}_{\text {emis }}^{\Delta, h_{\mathrm{c}}}$ only expresses the contribution by $\mathrm{MBO}$ and is much smaller than the daytime emissions from isoprene and MBO. Therefore, although the relative contributions from chemistry and deposition for isoprene + MBO are $100 \%$ all together, their absolute contributions to the overall concentration changes are negligible. The chemical loss for monoterpenes and isoprene + MBO is important throughout the boundary layer, but inside the canopy the monthly-averaged chemical destruction tendency $\bar{Q}_{\text {chem }}^{\Delta, h_{\mathrm{c}}}$ is only $5-10 \%$ of $\bar{Q}_{\text {emis }}^{\Delta, h_{\mathrm{c}}}$ (Figs. 5a and 6b).

Sesquiterpenes, which belong to the category Cemischem, are efficiently destroyed by chemical reactions with $\mathrm{O}_{3}$ within the canopy. Consequently, the diurnal pattern in $\bar{Q}_{\text {chem }}^{\Delta, h_{\mathrm{c}}}$ for sesquiterpenes corresponds to the diurnal variations in the $\mathrm{O}_{3}$ concentration. However, the relative contributions of different source and sink terms only change a little during the whole day (Fig. 6c).

In the third category, Cemis-depo, diurnal changes in the deposition process, e.g. due to changes in mixing conditions, stomatal opening, and leaf or needle surface properties, can result in weak or downward fluxes at the canopy top in the morning when the emission is weak (Fig. 6df). For formaldehyde, the average absolute value of $\bar{Q}_{\text {depo }}^{\Delta, h_{\mathrm{c}}}$ is about $0.90 \mu \mathrm{g} \mathrm{m}^{-3} \mathrm{~h}^{-1}$ larger than $\bar{Q}_{\text {emis }}^{\Delta, h_{\mathrm{c}}}$, resulting in a downward turbulent flux at the canopy top during the whole day (Fig. 7a). The daily variation reflected by the occurrence of bidirectional fluxes also indicates the difficulty of measuring the actual emission rates of those compounds.

When the turbulent transport and the dry deposition terms are the only source and sink within the canopy, e.g. in the category Cdepo, only downward flux can be observed (Fig. 7bd). For pinic acid and $\mathrm{BCSOZOH}$, which have very high $H$ values $\left(1.70 \times 10^{9}\right.$ and $\left.9.09 \times 10^{7} \mathrm{M} \mathrm{atm}^{-1}\right)$, the absolute values of $\bar{Q}_{\text {depo }}^{\Delta, h_{\mathrm{c}}}$ have midnight peaks due to higher RH, which results in a larger wet skin fraction on leaf surface and thus facilitates the deposition of soluble gases onto the leaf surface.

For the category Cchem-depo, the daytime chemical production plays a significant or dominant role in the concentration variations because the oxidation products ISOP34NO3 and ISOP34OOH are produced from a chain of chemical reactions starting with isoprene oxidation during the daytime (Fig. 7e and f). For ISOP34NO3, $\bar{Q}_{\text {chem }}^{\Delta, h_{\mathrm{c}}}$ is even larger than $\bar{Q}_{\text {depo }}^{\Delta, h_{\mathrm{c}}}$ at noon, causing weak upward fluxes over the canopy, whereas for ISOP34OOH, the deposition sink is always larger than the chemical production.

\subsection{Vertical profiles of in-canopy sources and sinks}

In order to investigate how different source and sink terms are distributed inside the canopy, the monthly-averaged vertical profiles of $\bar{Q}_{n}^{\Delta}$ (Eq. A3) for all the selected compounds are plotted in Figs. 8 and 9. Here the $\bar{Q}_{n}^{\Delta}$ values at each layer are weighted by $\Delta z_{i} / h_{\mathrm{c}}$ ( $i$ is the layer index) to represent layerspecific actual contributions to monthly-averaged $\bar{Q}_{n}^{\Delta, h_{\mathrm{c}}}$. 

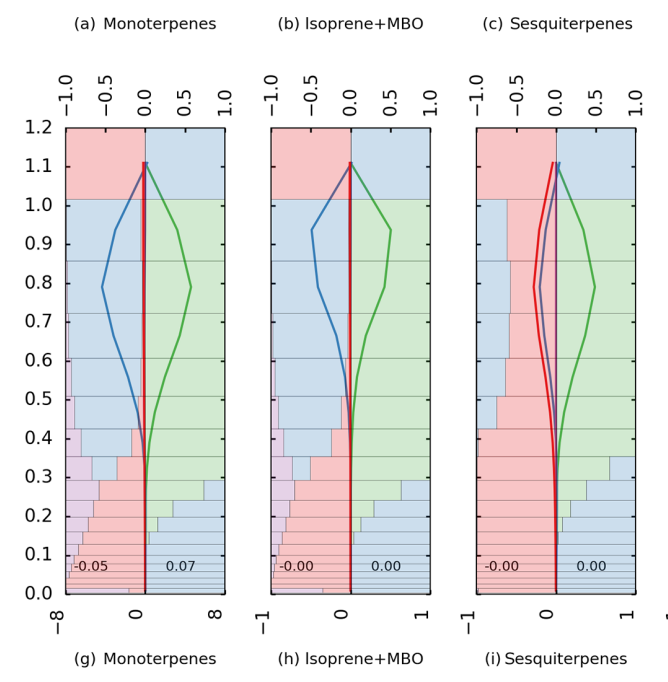

(d) Acetaldehyde

(e) Methanol

(f) Acetone
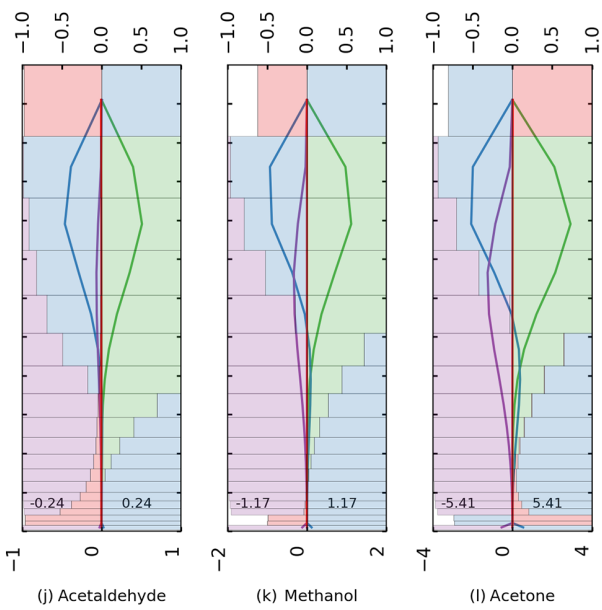

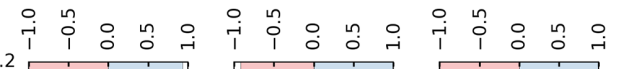
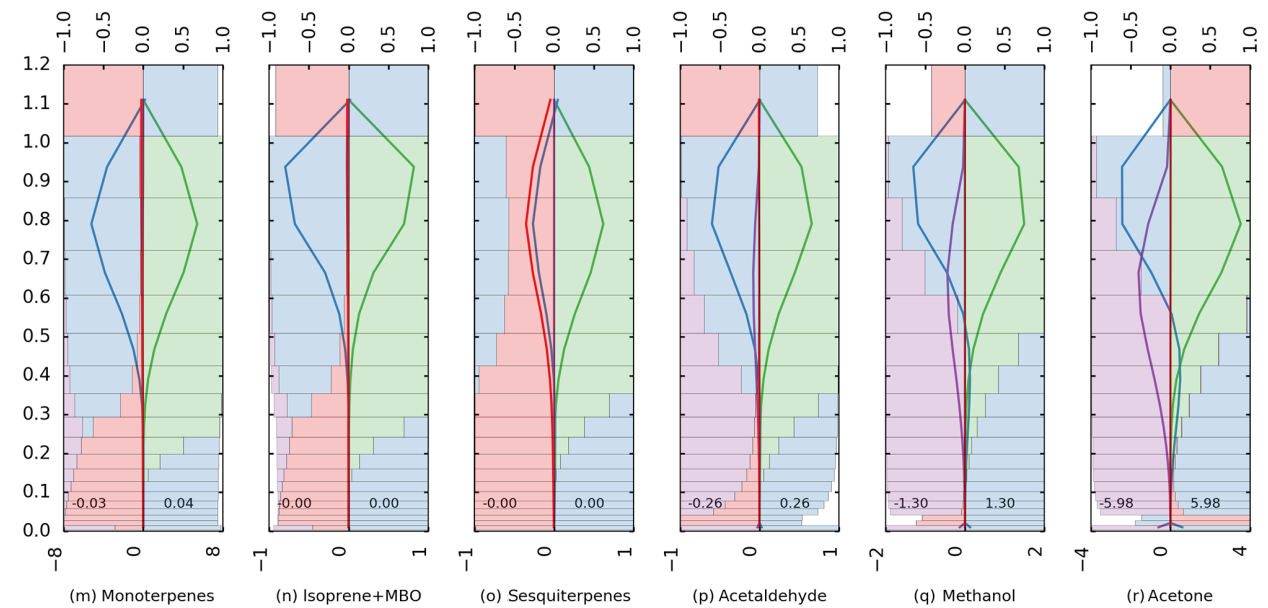

$\bar{Q}_{r e, n}^{\Delta}$
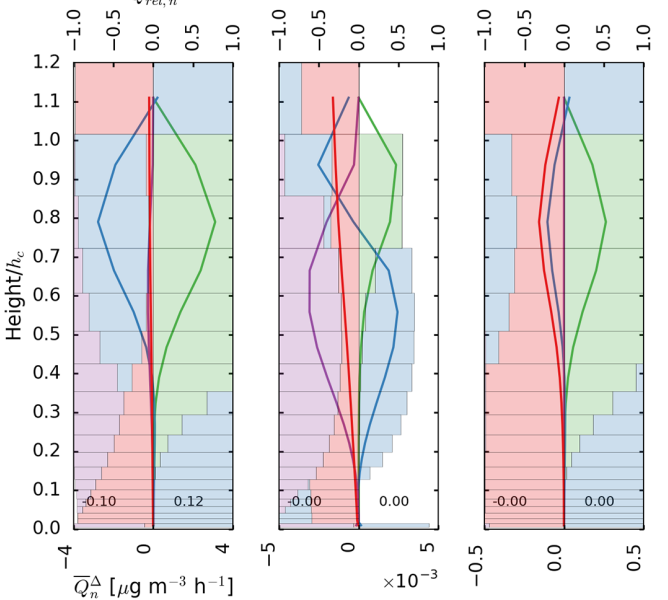

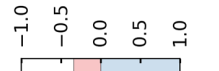

(q) Methanol

(r) Acetone
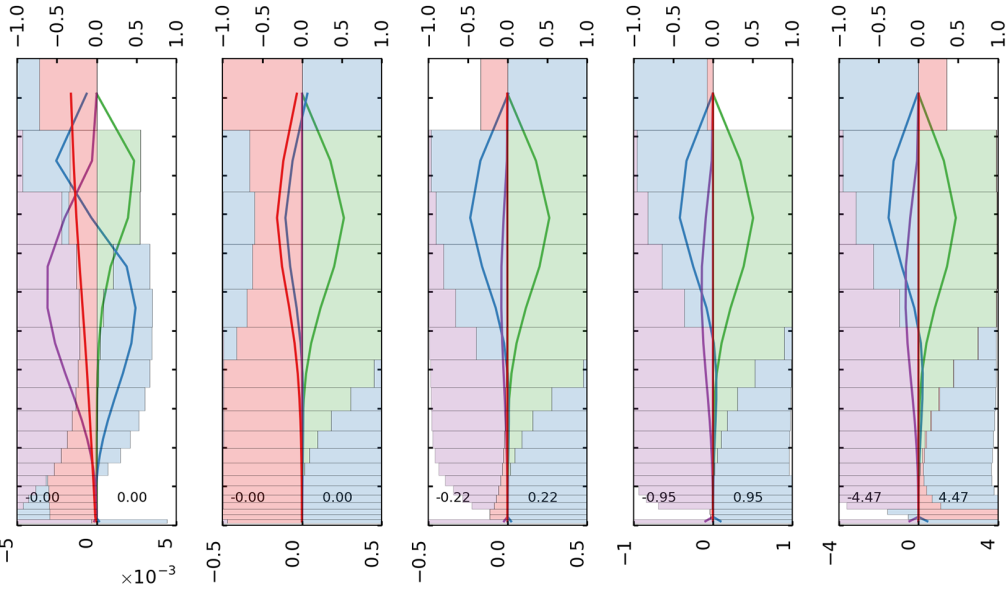

Figure 8. Modelled monthly-averaged vertical profiles of weighted $\bar{Q}_{n}^{\Delta}$ (solid lines) and the relative contributions $\bar{Q}_{\text {rel }, n}^{\Delta}$ (bars) of gas emissions (green), net chemical production and loss (red), turbulent transport (blue), and gas dry deposition (purple) within the canopy for (a) monoterpenes, (b) isoprene + MBO, (c) acetaldehyde, (d) sesquiterpenes, (e) methanol, and (f) acetone. Panels (g) to (l) and panels (m) to $(\mathbf{r})$ are for the same compounds but the average is performed for daytime and nighttime, respectively. The height is normalized by the canopy height $\left(h_{\mathrm{c}}\right)$. The values of weighted $\bar{Q}_{n}^{\Delta}$ at the surface layer are divided by 10 for clarity. The original values at the surface layer for deposition (left) and transport (right) are shown as float numbers at the bottom for each plot. The $x$ labels and $y$ labels of (m) also apply to all the other panels. 

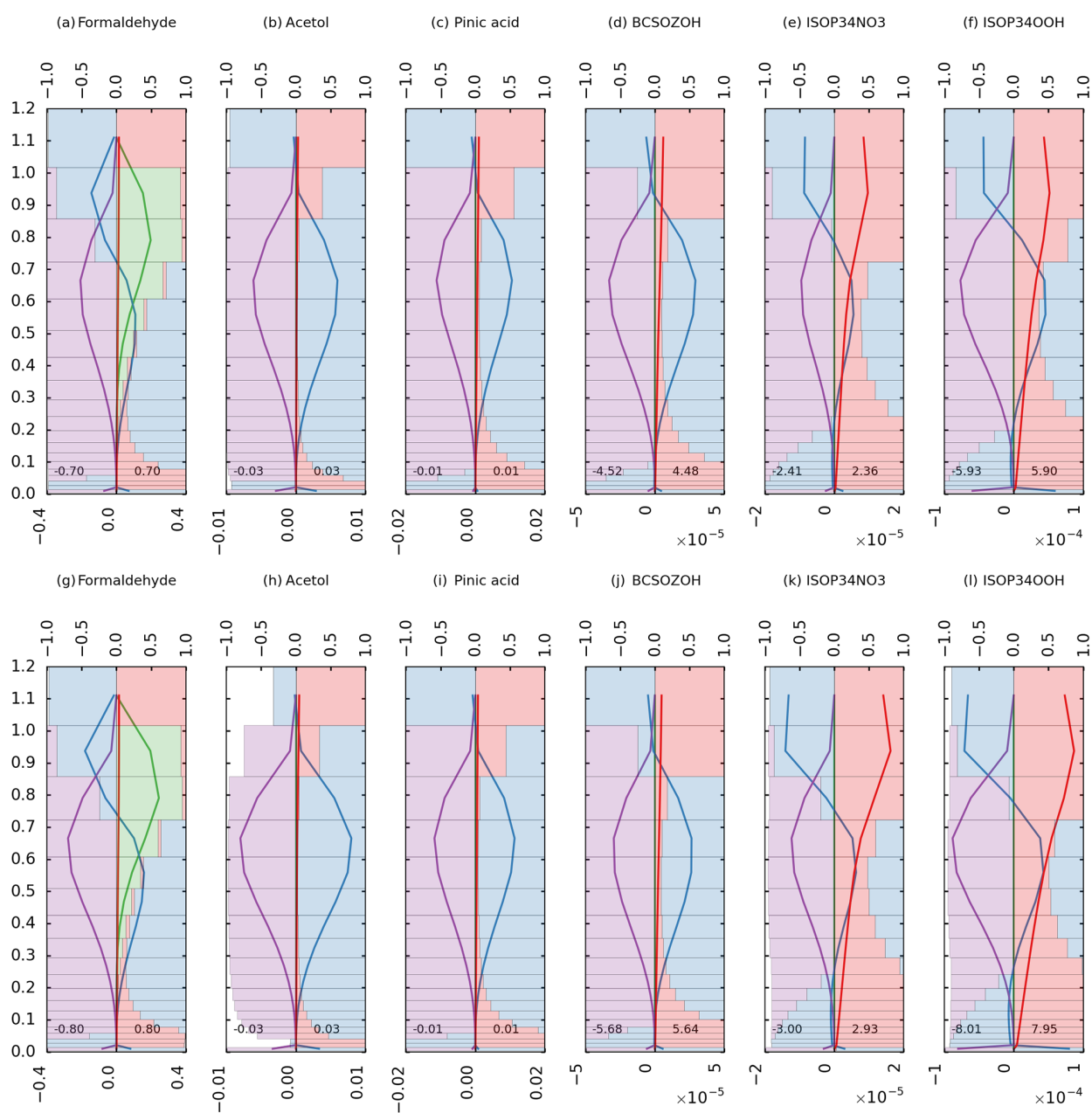

(n) Acetol

(o) Pinic acid

(p) BCSOZOH

(q) ISOP34NO3

(r) $150 \mathrm{OP} 3400 \mathrm{H}$
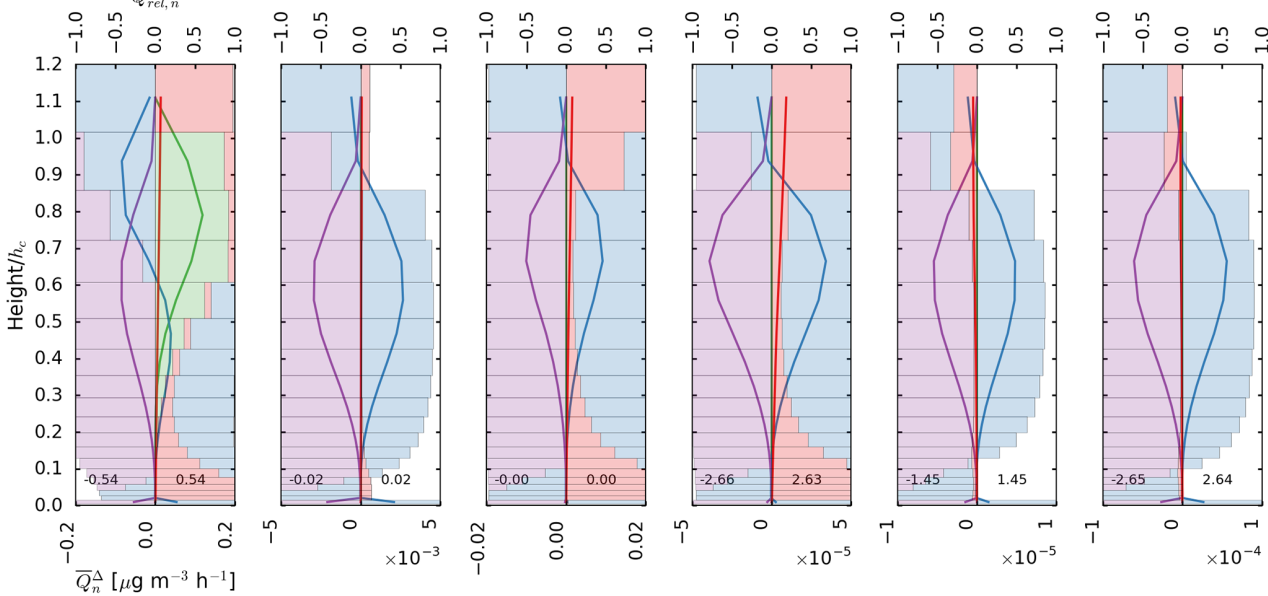

Figure 9. The same as Fig. 8 but for formaldehyde, acetol, pinic acid, BCSOZOH, ISOP34NO3, and ISOP34OOH. Note that the bottom numbers for BCSOZOH, ISOP34NO3, and ISOP34OOH also need to be scaled by $10^{-5}, 10^{-5}$, and $10^{-4}$, respectively. 
For all emitted compounds, the vertical distributions of emission source approximately follow the LAD profile with an upward shifting during the whole day, which implies that PAR and leaf temperature play a comparable role in emission rates in addition to the LAD. Due to strong PAR-dependent emissions, the maximum value of $\bar{Q}_{\text {emis }}^{\Delta}$ for isoprene $+\mathrm{MBO}$ locates at $\sim 16 \mathrm{~m}$, which is higher than that of other emitted compounds whose emissions are both PAR and temperature dependent (Figs. 8a-f and 9a). This results from the effect of relatively fast attenuation of PAR inside the canopy compared to the vertical temperature gradient (Figs. $1 b$ and $2 b$ ).

In fact, the vertical distributions of both PAR and leaf temperature depend on the LAD profile, which affects the incoming solar radiation. However, due to turbulent mixing, the air temperature distribution is more homogenous inside the canopy, which also reflected by the relatively small vertical gradient in leaf temperature. In contrast, PAR is attenuated within the canopy only as a function of LAD and therefore has larger vertical gradient.

For the BVOCs in categories Cemis-depo, Cdepo, and Cchem-depo, dry deposition is significant and even becomes the only dominant sink term for the non-emitted gases. The dry deposition rate above the soil layer is mainly determined by the LAD at each layer inside the canopy. Therefore, the dry deposition follows the vertical profile of LAD. In addition to the deposition onto vegetation surface, soil deposition provides an important sink similar to $\mathrm{O}_{3}$ for which the estimated soil deposition sink removes about $36 \%$ of all the $\mathrm{O}_{3}$ removed by the boreal forest (Zhou et al., 2017). For BVOCs with significant dry deposition sinks, the contribution of daily average soil deposition (including deposition onto understorey vegetation) to the total deposition varies from $11 \%$ (pinic acid) to $61 \%$ (ISOP34OOH). Without considering the soil deposition, most sources and sinks are located above a height that is about $0.4 h_{\mathrm{c}}$ for monoterpenes, isoprene $+\mathrm{MBO}$, sesquiterpenes, acetaldehyde, methanol, and acetone (Fig. 8a-f) and about $0.2 h_{\mathrm{c}}$ for formaldehyde, acetol, pinic acid, BCSOZOH, ISOP34NO3, and ISOP34OOH (Fig. 9a-f). Therefore, below 0.4 or $0.2 h_{\mathrm{c}}$ depending on specific compounds, the contributions of $\bar{Q}_{\mathrm{emis}}^{\Delta}, \bar{Q}_{\mathrm{chem}}^{\Delta}$, and $\bar{Q}_{\text {turb }}^{\Delta}$ can be neglected. This is also true for $\bar{Q}_{\text {depo }}^{\Delta}$ for the BVOCs with very weak soil deposition, e.g. monoterpenes, isoprene $+\mathrm{MBO}$, and sesquiterpenes (Fig. 8a-c).

The vertical profiles of the monthly-averaged total concentration tendencies $\bar{Q}_{n}^{\Delta}$ for selected gases, except isoprene $+\mathrm{MBO}$, ISOP34NO3, and ISOP34OOH, only change the magnitude during daytime and nighttime instead of profile patterns (Figs. 8g, i-1, m, o-r, 9g-j, m-p). At nighttime, the dry deposition is as important as the emission for isoprene + MBO within the canopy (Fig. 8n); however, their absolute contributions are too small compared to those during daytime, as can be also seen in the diurnal cycle (Fig. 6b). For the isoprene oxidation products ISOP34NO3 and ISOP34OOH, the deposition is compensated for by the downward turbulent fluxes without the chemical production during the nighttime, resulting in obvious net removal of the gases throughout the canopy (Fig. 9q and r). Moreover, at the canopy top and close to the surface, these compounds exhibit a clear imbalance between production and sink terms; however, the imbalance does not really affect the concentration change inside the canopy since the absolute in-canopy source and sink terms are all close to zero. During daytime, chemical sources of these two BVOCs, which are at a maximum at the canopy top and decrease inside the canopy, are larger than the deposition sinks above $\sim 14 \mathrm{~m}$ (Fig. 9k and l). Thus, the extra produced gases at these levels inside the canopy can then be transported to deeper inside the canopy, causing $\bar{Q}_{\text {turb }}^{\Delta}$ to change sign at $\sim 14 \mathrm{~m}$. This phenomenon of the change in sign of $\bar{Q}_{\text {turb }}^{\Delta}$ inside the canopy can also be seen for formaldehyde during both daytime and nighttime (Fig. 9a, g and m). In this case, $\bar{Q}_{\text {emis }}^{\Delta}$ is comparable with $\bar{Q}_{\text {depo }}^{\Delta}$, but its peak position is higher than that of $\bar{Q}_{\text {depo }}^{\Delta}$.

\section{Summary}

Based on the $\mathrm{O}_{3}$ dry deposition model developed in Zhou et al. (2017), a new multilayer gas dry deposition model extended from Wesely (1989) and Nguyen et al. (2015) was implemented into the 1-D chemical transport model SOSAA. This model enabled the calculation of dry deposition processes within a forest canopy for all the gas compounds included in a chemistry scheme.

Using this model we analysed the monthly-averaged in-canopy sources and sinks of 12 featured BVOCs at SMEAR II in July 2010. Several general behaviours of the selected BVOCs inside a boreal canopy were revealed. Throughout the whole day, $\sim 86 \%$ of monoterpenes and $\sim 93 \%$ of isoprene + MBO was transported out of the canopy after emitted from the canopy. However, the canopy acted as a sink for isoprene $+\mathrm{MBO}$ at nighttime when they were not emitted. Conversely, most of the emitted sesquiterpenes were oxidized inside the canopy with only about $29 \%$ ventilated out. For the BVOCs with bidirectional fluxes, e.g. acetaldehyde, methanol, acetone, and formaldehyde, a large portion or even all of the emitted gases were removed by dry deposition inside the canopy. The soil deposition contributed over $40 \%$ of the overall deposition sink. Moreover, the relative contributions of dry deposition sinks compared to emissions were maximum at dawn when the highest $\mathrm{RH}$ values occurred. Acetol, pinic acid, and BCSOZOH were removed by dry deposition inside the canopy, with less than $20 \%$ compensated for by chemical production, resulting in dominant downward fluxes throughout the whole day. ISOP34NO3 and ISOP34OOH showed behaviours similar to acetol at nighttime. However, in daytime, the chemical productions from isoprene oxidation reactions were comparable with deposi- 
tion sinks, which could even lead to a slightly upward flux at the canopy top at noon for ISOP34NO3.

The vertical distributions of in-canopy sources and sinks for all the gases had several common features. The vertical distribution of dry deposition onto vegetation surfaces always followed the LAD variation, which peaked at about $0.6 h_{\mathrm{c}}$ in this study. The peaks of emission sources were from 0.8 to $0.9 h_{\mathrm{c}}$, which was higher than dry deposition because the attenuated PAR and leaf temperature reduced the emission rate inside the canopy. The vertical profile of chemical sinks for sesquiterpenes was nearly the same as their emissions since they were mostly oxidized right after being emitted. The chemical productions for ISOP34NO3 and ISOP34OOH were maximum around the canopy top where the isoprene emission peaked and the radiation was high.

According to the significance of different source and sink terms, the selected BVOCs were classified into five categories: Cemis (monoterpenes, isoprene $+\mathrm{MBO}$ ), Cemis-chem (sesquiterpenes), Cemis-depo (acetaldehyde, methanol, acetone, formaldehyde), Cdepo (acetol, pinic acid, $\mathrm{BCSOZOH}$ ), and Cchem-depo (ISOP34OOH, ISOP34NO3), where the subscripts represented the significant terms. Generally speaking, the classifications for these BVOCs were expected to be applicable in other canopy types at least in summertime.

This study has provided a method to quantify the proportion of dry deposition sinks for various BVOCs that can be applied in large-scale models in the future. On the basis of the analysis of 12 selected BVOCs or groups of BVOCs in this study, a large number of other compounds with similar properties can be represented by being classified into the five categories mentioned above. For example, OVOCs most likely belong to categories Cdepo and Cchem-depo, which indicates that dry deposition can not be neglected when their sources and sinks are investigated. In addition, the categories Cemis-chem and Cemis-depo imply that the simulation of individual processes is necessary to help further analyse the measured emission data of such gases and thus obtain a more accurate estimation of BVOC exchange.
This study has shown that dry deposition of oxidation products of precursor gases as well as other BVOCs could be a potentially important feature of improving our understanding and quantification of BVOC exchange. However, such assessments are largely limited by available observations that could further corroborate the correctness of the simulated deposition processes as presented in this study. Furthermore, this study stresses the necessity of applying a canopy exchange modelling system for a detailed analysis of BVOC exchange regimes within and above a boreal forest canopy, instead of applying a big-leaf representation without considering the interactions between emissions, chemistry, turbulent transport, and deposition.

Data availability. The code for calculating the Henry's law constants and reactivity factors is attached in the Supplement. The whole SOSAA code is available by contacting Michael Boy (michael.boy@helsinki.fi) or Zhou Putian (putian.zhou@helsinki.fi). 


\section{Appendix A: Accumulated and integrated source} and sink terms

The output time step in the model is $30 \mathrm{~min}$; thus, the accumulated values of $Q_{n}^{t}$ ( $n=$ emis, chem, depo, turb) during the previous $30 \mathrm{~min}$ are computed and saved instead of the instantaneous values:

$$
\begin{aligned}
& \frac{1}{30 \min } \int_{t-30 \min }^{t}\left(\frac{\partial[X]}{\partial t}=Q_{\text {emis }}^{t}+Q_{\text {chem }}^{t}\right. \\
& \left.+Q_{\text {depo }}^{t}+Q_{\text {turb }}^{t}\right) \mathrm{d} t \\
& \frac{[X]^{t}-[X]^{t-30 \min }}{30 \min }=\bar{Q}_{\text {emis }}^{\Delta}+\bar{Q}_{\text {chem }}^{\Delta}+\bar{Q}_{\text {depo }}^{\Delta}+\bar{Q}_{\text {turb }}^{\Delta} \\
& \bar{Q}_{n}^{\Delta}=\frac{1}{30 \min } \int_{t-30 \min }^{t} Q_{n}^{t} \mathrm{~d} t .
\end{aligned}
$$

The superscript $\Delta$ represents a $30 \mathrm{~min}$ integration period. Moreover, in order to analyse the integrated sources and sinks within the canopy, the in-canopy gas concentration change during the previous $30 \mathrm{~min}$ is calculated as

$$
\begin{aligned}
& \frac{1}{h_{\mathrm{c}}} \int_{0}^{h_{\mathrm{c}}}\left(\frac{[X]^{t}-[X]^{t-30 \mathrm{~min}}}{30 \mathrm{~min}}=\bar{Q}_{\text {emis }}^{\Delta}+\bar{Q}_{\text {chem }}^{\Delta}\right. \\
& \left.\quad+\bar{Q}_{\text {depo }}^{\Delta}+\bar{Q}_{\text {turb }}^{\Delta}\right) \mathrm{d} z
\end{aligned}
$$

$$
\bar{Q}_{n}^{\Delta, h_{\mathrm{c}}}=\frac{1}{h_{\mathrm{c}}} \int_{0}^{h_{\mathrm{c}}} \bar{Q}_{n}^{\Delta} \mathrm{d} z .
$$

Similarly, the superscripts $\Delta$ and $h_{\mathrm{c}}$ all together represent the integration over the previous $30 \mathrm{~min}$ and from surface to canopy height. Here the positive (negative) $\bar{Q}_{\text {turb }}^{\Delta, h_{\mathrm{c}}}$ value indicates the downward (upward) flux at the canopy top resulting in positive (negative) contribution to the in-canopy amount of compound $X$.

In addition, the relative contributions of individual sources and sinks are also computed. First, the maximum absolute value between total source and total sink is calculated:

$$
\begin{aligned}
Q_{\max } & =\max \left(Q_{\mathrm{emis}}+\max \left(Q_{\mathrm{chem}}, 0\right)+\max \left(Q_{\mathrm{turb}}, 0\right),\right. \\
& \left.-\left(Q_{\mathrm{depo}}+\min \left(Q_{\mathrm{chem}}, 0\right)+\min \left(Q_{\text {turb }}, 0\right)\right)\right) .
\end{aligned}
$$

Here we assume that $Q_{\text {emis }}$ is always positive while $Q_{\text {depo }}$ is always negative. $Q_{\text {chem }}$ and $Q_{\text {turb }}$ can be either positive or negative. Then the relative contributions are obtained:

$Q_{\mathrm{rel}, n}=\frac{Q_{n}}{Q_{\max }}$.

Hence, the values of $Q_{\text {rel }, n}$ are in the range of -1 to 1 . Here $Q_{n}$ can be $Q_{n}^{t}, \bar{Q}_{n}^{\Delta}$, or $\bar{Q}_{n}^{\Delta, h_{\mathrm{c}}}$, corresponding to $Q_{\mathrm{rel}, n}^{t}$, $\bar{Q}_{\mathrm{rel}, n}^{\Delta}$, or $\bar{Q}_{\mathrm{rel}, n}^{\Delta, h_{\mathrm{c}}}$. 


\author{
The Supplement related to this article is available \\ online at https://doi.org/10.5194/acp-17-14309-2017- \\ supplement.
}

Author contributions. PZ developed the deposition code in SOSAA, made the simulation runs, and wrote the main part of paper. LG provided the original deposition code and proposed the paper structure. DT contributed to the discussions related to air chemistry and BVOC emissions. ÜR contributed to the discussions related to BVOC fluxes and their source and sink terms. PR provided the measurement data of BVOC concentrations and fluxes and contributed to the discussions of measurement method. MPR selected the featured BVOCs and contributed to the discussions of air chemistry. DC contributed to the configuration of the simulation runs. MB provided the SOSAA code and proposed the main concept and structure of this paper. All the authors contributed to revising the paper.

Competing interests. The authors declare that they have no conflict of interest.

Special issue statement. This article is part of the special issue "Interactions between climate change and the Cryosphere: SVALI, DEFROST, CRAICC (2012-2016) (TC/ACP/BG inter-journal SI)". It is not associated with a conference.

Acknowledgements. We acknowledge the support from the Academy of Finland Centre of Excellence (project no. 307331), Maj and Tor Nessling funding, the Nordic Centre of Excellence eSTICC (project no. 57001), and the computational resources from CSC - IT Center for Science, Finland. Ditte Taipale acknowledges the support from the European Regional Development Fund (Centre of Excellence EcolChange). Matti Petteri Rissanen acknowledges the funding from the Academy of Finland (project no. 299574). Dean Chen acknowledges the China Scholarship Council (CSC) for financial support.

Edited by: Steffen M. Noe

Reviewed by: two anonymous referees

\section{References}

Aalto, J., Kolari, P., Hari, P., Kerminen, V.-M., Schiestl-Aalto, P., Aaltonen, H., Levula, J., Siivola, E., Kulmala, M., and Bäck, J.: New foliage growth is a significant, unaccounted source for volatiles in boreal evergreen forests, Biogeosciences, 11, 13311344, https://doi.org/10.5194/bg-11-1331-2014, 2014.

Aaltonen, H., Pumpanen, J., Pihlatie, M., Hakola, H., Hellén, H., Kulmala, L., Vesala, T., and Bäck, J.: Boreal pine forest floor biogenic volatile organic compound emissions peak in early summer and autumn, Agr. Forest Meteorol., 151, 682-691, https://doi.org/10.1016/j.agrformet.2010.12.010, 2011.
Aaltonen, H., Aalto, J., Kolari, P., Pihlatie, M., Pumpanen, J., Kulmala, M., Nikinmaa, E., Vesala, T., and Bäck, J.: Continuous VOC flux measurements on boreal forest floor, Plant Soil, 369, 241-256, https://doi.org/10.1007/s11104-012-1553-4, 2013.

Altimir, N., Kolari, P., Tuovinen, J.-P., Vesala, T., Bäck, J., Suni, T., Kulmala, M., and Hari, P.: Foliage surface ozone deposition: a role for surface moisture?, Biogeosciences, 3, 209-228, https://doi.org/10.5194/bg-3-209-2006, 2006.

Ashworth, K., Chung, S. H., Griffin, R. J., Chen, J., Forkel, R., Bryan, A. M., and Steiner, A. L.: FORest Canopy Atmosphere Transfer (FORCAsT) 1.0: a 1-D model of biosphereatmosphere chemical exchange, Geosci. Model Dev., 8, 37653784, https://doi.org/10.5194/gmd-8-3765-2015, 2015.

Atkinson, R.: Gas-Phase Tropospheric Chemistry of Volatile Organic Compounds: 1. Alkanes and Alkenes, J. Phys. Chem. Ref. Data, 26, 215-290, https://doi.org/10.1063/1.556012, 1997.

Aumont, B., Szopa, S., and Madronich, S.: Modelling the evolution of organic carbon during its gas-phase tropospheric oxidation: development of an explicit model based on a self generating approach, Atmos. Chem. Phys., 5, 2497-2517, https://doi.org/10.5194/acp-5-2497-2005, 2005.

Bäck, J., Aalto, J., Henriksson, M., Hakola, H., He, Q., and Boy, M.: Chemodiversity of a Scots pine stand and implications for terpene air concentrations, Biogeosciences, 9, 689-702, https://doi.org/10.5194/bg-9-689-2012, 2012.

Bamberger, I., Hörtnagl, L., Ruuskanen, T. M., Schnitzhofer, R., Müller, M., Graus, M., Karl, T., Wohlfahrt, G., and Hansel, A.: Deposition fluxes of terpenes over grassland, J. Geophys. Res.Atmos., 116, d14305, https://doi.org/10.1029/2010JD015457, 2011.

Boy, M., Sogachev, A., Lauros, J., Zhou, L., Guenther, A., and Smolander, S.: SOSA - a new model to simulate the concentrations of organic vapours and sulphuric acid inside the ABL Part 1: Model description and initial evaluation, Atmos. Chem. Phys., 11, 43-51, https://doi.org/10.5194/acp-11-43-2011, 2011.

Boy, M., Mogensen, D., Smolander, S., Zhou, L., Nieminen, T., Paasonen, P., Plass-Dülmer, C., Sipilä, M., Petäjä, T., Mauldin, L., Berresheim, H., and Kulmala, M.: Oxidation of $\mathrm{SO}_{2}$ by stabilized Criegee intermediate ( $\mathrm{SCI}$ ) radicals as a crucial source for atmospheric sulfuric acid concentrations, Atmos. Chem. Phys., 13, 3865-3879, https://doi.org/10.5194/acp-13-3865-2013, 2013.

Bryan, A. M., Bertman, S. B., Carroll, M. A., Dusanter, S., Edwards, G. D., Forkel, R., Griffith, S., Guenther, A. B., Hansen, R. F., Helmig, D., Jobson, B. T., Keutsch, F. N., Lefer, B. L., Pressley, S. N., Shepson, P. B., Stevens, P. S., and Steiner, A. L.: In-canopy gas-phase chemistry during CABINEX 2009: sensitivity of a 1$\mathrm{D}$ canopy model to vertical mixing and isoprene chemistry, Atmos. Chem. Phys., 12, 8829-8849, https://doi.org/10.5194/acp12-8829-2012, 2012.

Damian, V., Sandu, A., Damian, M., Potra, F., and Carmichael, G. R.: The kinetic preprocessor KPP-a software environment for solving chemical kinetics, Comput. Chem. Eng., 26, 1567-1579, https://doi.org/10.1016/S0098-1354(02)00128-X, 2002.

Dee, D. P., Uppala, S. M., Simmons, A. J., Berrisford, P., Poli, P., Kobayashi, S., Andrae, U., Balmaseda, M. A., Balsamo, G., Bauer, P., Bechtold, P., Beljaars, A. C. M., van de Berg, L., Bidlot, J., Bormann, N., Delsol, C., Dragani, R., Fuentes, M., Geer, A. J., Haimberger, L., Healy, S. B., Hersbach, H., Hólm, E. V., Isaksen, L., Kållberg, P., Köhler, M., Matricardi, M., McNally, 
A. P., Monge-Sanz, B. M., Morcrette, J.-J., Park, B.-K., Peubey, C., de Rosnay, P., Tavolato, C., Thépaut, J.-N., and Vitart, F.: The ERA-Interim reanalysis: configuration and performance of the data assimilation system, Q. J. Roy. Meteor. Soc., 137, 553-597, https://doi.org/10.1002/qj.828, 2011.

DiGangi, J. P., Boyle, E. S., Karl, T., Harley, P., Turnipseed, A., Kim, S., Cantrell, C., Maudlin III, R. L., Zheng, W., Flocke, F., Hall, S. R., Ullmann, K., Nakashima, Y., Paul, J. B., Wolfe, G. M., Desai, A. R., Kajii, Y., Guenther, A., and Keutsch, F. N.: First direct measurements of formaldehyde flux via eddy covariance: implications for missing in-canopy formaldehyde sources, Atmos. Chem. Phys., 11, 10565-10578, https://doi.org/10.5194/acp-11-10565-2011, 2011.

Ganzeveld, L. and Lelieveld, J.: Dry deposition parameterization in a chemistry general circulation model and its influence on the distribution of reactive trace gases, J. Geophy. Res., 100, 20999_ 21012, 1995.

Ganzeveld, L., Lelieveld, J., and Roelofs, G.-J.: A dry deposition parameterization for sulfur oxides in a chemistry and general circulation model, J. Geophys. Res.-Atmos., 103, 5679-5694, https://doi.org/10.1029/97JD03077, 1998.

Ganzeveld, L., Bouwman, L., Stehfest, E., van Vuuren, D. P., Eickhout, B., and Lelieveld, J.: Impact of future land use and land cover changes on atmospheric chemistryclimate interactions, J. Geophys. Res.-Atmos., 115, d23301, https://doi.org/10.1029/2010JD014041, 2010.

Ganzeveld, L. N., Lelieveld, J., Dentener, F. J., Krol, M. C., and Roelofs, G.-J.: Atmosphere-biosphere trace gas exchanges simulated with a single-column model, J. Geophys. Res., 107, ACH 8-1-ACH 8-21, https://doi.org/10.1029/2001JD000684, 2002.

Goldstein, A. H. and Galbally, I. E.: Known and Unexplored Organic Constituents in the Earth's Atmosphere, Environ. Sci. Technol., 41, 1514-1521, https://doi.org/10.1021/es072476p, 2007.

Grace, J., Fasehun, F. E., and Dixon, M.: Boundary layer conductance of the leaves of some tropical timber trees, Plant Cell Environ., 3, 443-450, https://doi.org/10.1111/13653040.ep11586917, 1980.

Guenther, A., Karl, T., Harley, P., Wiedinmyer, C., Palmer, P. I., and Geron, C.: Estimates of global terrestrial isoprene emissions using MEGAN (Model of Emissions of Gases and Aerosols from Nature), Atmos. Chem. Phys., 6, 3181-3210, https://doi.org/10.5194/acp-6-3181-2006, 2006.

Guenther, A. B., Jiang, X., Heald, C. L., Sakulyanontvittaya, T., Duhl, T., Emmons, L. K., and Wang, X.: The Model of Emissions of Gases and Aerosols from Nature version 2.1 (MEGAN2.1): an extended and updated framework for modeling biogenic emissions, Geosci. Model Dev., 5, 1471-1492, https://doi.org/10.5194/gmd-5-1471-2012, 2012.

Haapanala, S., Rinne, J., Hakola, H., Hellén, H., Laakso, L., Lihavainen, H., Janson, R., O'Dowd, C., and Kulmala, M.: Boundary layer concentrations and landscape scale emissions of volatile organic compounds in early spring, Atmos. Chem. Phys., 7, 1869-1878, https://doi.org/10.5194/acp-7-1869-2007, 2007.

Hakola, H., Tarvainen, V., Bäck, J., Ranta, H., Bonn, B., Rinne, J., and Kulmala, M.: Seasonal variation of mono- and sesquiterpene emission rates of Scots pine, Biogeosciences, 3, 93-101, https://doi.org/10.5194/bg-3-93-2006, 2006.
Hallquist, M., Wenger, J. C., Baltensperger, U., Rudich, Y., Simpson, D., Claeys, M., Dommen, J., Donahue, N. M., George, C., Goldstein, A. H., Hamilton, J. F., Herrmann, H., Hoffmann, T., Iinuma, Y., Jang, M., Jenkin, M. E., Jimenez, J. L., Kiendler-Scharr, A., Maenhaut, W., McFiggans, G., Mentel, Th. F., Monod, A., Prévôt, A. S. H., Seinfeld, J. H., Surratt, J. D., Szmigielski, R., and Wildt, J.: The formation, properties and impact of secondary organic aerosol: current and emerging issues, Atmos. Chem. Phys., 9, 5155-5236, https://doi.org/10.5194/acp9-5155-2009, 2009.

Hari, P. and Kulmala, M.: Station for Measuring EcosystemAtmosphere Relations (SMEAR II), Boreal. Environ. Res., 10, 315-322, 2005.

Hicks, B. B., Baldocchi, D. D., Meyers, T. P., Hosker, R. P., and Matt, D. R.: A preliminary multiple resistance routine for deriving dry deposition velocities from measured quantities, Water Air Soil Poll., 36, 311-330, https://doi.org/10.1007/BF00229675, 1987.

Hine, J. and Mookerjee, P. K.: Structural effects on rates and equilibriums. XIX. Intrinsic hydrophilic character of organic compounds. Correlations in terms of structural contributions, J. Org. Chem., 40, 292-298, https://doi.org/10.1021/jo00891a006, 1975.

Hodzic, A., Aumont, B., Knote, C., Madronich, S., and Tyndall, G.: Volatility dependence of Henry's law constants of condensable organics: Application to estimate depositional loss of secondary organic aerosols, Geophys. Res. Lett., 41, 4795-4804, https://doi.org/10.1002/2014GL060649, 2014.

Ilvesniemi, H., Levula, J., Ojansuu, R., Kolari, P., Kulmala, L., Pumpanen, J., Launiainen, S., Vesala, T., and Nikinmaa, E.: Long-term measurements of the carbon balance of a boreal Scots pine dominated forest ecosystem, Boreal. Environ. Res., 14, 731753, 2009.

Jacob, D. J., Field, B. D., Li, Q., Blake, D. R., de Gouw, J., Warneke, C., Hansel, A., Wisthaler, A., Singh, H. B., and Guenther, A.: Global budget of methanol: Constraints from atmospheric observations, J. Geophys. Res.-Atmos., 110, d08303, https://doi.org/10.1029/2004JD005172, 2005.

Janson, R. and de Serves, C.: Acetone and monoterpene emissions from the boreal forest in northern Europe, Atmos. Environ., 35, 4629-4637, https://doi.org/10.1016/S1352-2310(01)00160$1,2001$.

Jenkin, M. E., Saunders, S. M., and Pilling, M. J.: The tropospheric degradation of volatile organic compounds: a protocol for mechanism development, Atmos. Environ., 31, 81-104, https://doi.org/10.1016/S1352-2310(96)00105-7, 1997.

Jenkin, M. E., Wyche, K. P., Evans, C. J., Carr, T., Monks, P. S., Alfarra, M. R., Barley, M. H., McFiggans, G. B., Young, J. C., and Rickard, A. R.: Development and chamber evaluation of the MCM v3.2 degradation scheme for $\beta$-caryophyllene, Atmos. Chem. Phys., 12, 5275-5308, https://doi.org/10.5194/acp12-5275-2012, 2012.

Karl, T., Harley, P., Guenther, A., Rasmussen, R., Baker, B., Jardine, K., and Nemitz, E.: The bi-directional exchange of oxygenated VOCs between a loblolly pine (Pinus taeda) plantation and the atmosphere, Atmos. Chem. Phys., 5, 3015-3031, https://doi.org/10.5194/acp-5-3015-2005, 2005.

Karl, T., Harley, P., Emmons, L., Thornton, B., Guenther, A., Basu, C., Turnipseed, A., and Jardine, K.: Efficient Atmospheric 
Cleansing of Oxidized Organic Trace Gases by Vegetation, Science, 330, 816-819, https://doi.org/10.1126/science.1192534, 2010.

Khan, M., Cooke, M., Utembe, S., Archibald, A., Maxwell, P., Morris, W., Xiao, P., Derwent, R., Jenkin, M., Percival, C., Walsh, R., Young, T., Simmonds, P., Nickless, G., O'Doherty, S., and Shallcross, D.: A study of global atmospheric budget and distribution of acetone using global atmospheric model STOCHEM-CRI, Atmos. Environ., 112, 269-277, https://doi.org/10.1016/j.atmosenv.2015.04.056, 2015.

Knote, C., Hodzic, A., and Jimenez, J. L.: The effect of dry and wet deposition of condensable vapors on secondary organic aerosols concentrations over the continental US, Atmos. Chem. Phys., 15, 1-18, https://doi.org/10.5194/acp-15-1-2015, 2015.

Korhonen, H., Lehtinen, K. E. J., and Kulmala, M.: Multicomponent aerosol dynamics model UHMA: model development and validation, Atmos. Chem. Phys., 4, 757-771, https://doi.org/10.5194/acp-4-757-2004, 2004.

Kulmala, M., Maso, M. D., Mäkelä, J. M., Pirjola, L., Väkevä, M., Aalto, P., Miikkulainen, P., Hämeri, K., and O'Dowd, C. D.: On the formation, growth and composition of nucleation mode particles, Tellus B, 53, 479-490, https://doi.org/10.1034/j.16000889.2001.530411.x, 2001.

Kurtén, T., Zhou, L., Makkonen, R., Merikanto, J., Räisänen, P., Boy, M., Richards, N., Rap, A., Smolander, S., Sogachev, A., Guenther, A., Mann, G. W., Carslaw, K., and Kulmala, M.: Large methane releases lead to strong aerosol forcing and reduced cloudiness, Atmos. Chem. Phys., 11, 6961-6969, https://doi.org/10.5194/acp-11-6961-2011, 2011.

Laffineur, Q., Aubinet, M., Schoon, N., Amelynck, C., Müller, J.F., Dewulf, J., Van Langenhove, H., Steppe, K., and Heinesch, B.: Abiotic and biotic control of methanol exchanges in a temperate mixed forest, Atmos. Chem. Phys., 12, 577-590, https://doi.org/10.5194/acp-12-577-2012, 2012.

Launiainen, S., Katul, G. G., Grönholm, T., and Vesala, T.: Partitioning ozone fluxes between canopy and forest floor by measurements and a multi-layer model, Agr. Forest Meteorol., 173, 85-99, 2013.

Lindfors, V. and Laurila, T.: Biogenic volatile organic compound (VOC) emissions from forests in Finland, Boreal Environ. Res., 5, 95-113, 2000.

Mäki, M., Heinonsalo, J., Hellén, H., and Bäck, J.: Contribution of understorey vegetation and soil processes to boreal forest isoprenoid exchange, Biogeosciences, 14, 1055-1073, https://doi.org/10.5194/bg-14-1055-2017, 2017.

Meyers, T. P.: The sensitivity of modeled $\mathrm{SO}_{2}$ fluxes and profiles to stomatal and boundary layer resistances, Water Air Soil Poll., 35, 261-278, https://doi.org/10.1007/BF00290935, 1987.

Meylan, W. M. and Howard, P. H.: Bond contribution method for estimating henry's law constants, Environ. Toxicol. Chem., 10, 1283-1293, https://doi.org/10.1002/etc.5620101007, 1991.

Millet, D. B., Guenther, A., Siegel, D. A., Nelson, N. B., Singh, H. B., de Gouw, J. A., Warneke, C., Williams, J., Eerdekens, G., Sinha, V., Karl, T., Flocke, F., Apel, E., Riemer, D. D., Palmer, P. I., and Barkley, M.: Global atmospheric budget of acetaldehyde: 3-D model analysis and constraints from in-situ and satellite observations, Atmos. Chem. Phys., 10, 3405-3425, https://doi.org/10.5194/acp-10-3405-2010, 2010.
Mogensen, D., Smolander, S., Sogachev, A., Zhou, L., Sinha, V., Guenther, A., Williams, J., Nieminen, T., Kajos, M. K., Rinne, J., Kulmala, M., and Boy, M.: Modelling atmospheric OH-reactivity in a boreal forest ecosystem, Atmos. Chem. Phys., 11, 97099719, https://doi.org/10.5194/acp-11-9709-2011, 2011.

Mogensen, D., Gierens, R., Crowley, J. N., Keronen, P., Smolander, S., Sogachev, A., Nölscher, A. C., Zhou, L., Kulmala, M., Tang, M. J., Williams, J., and Boy, M.: Simulations of atmospheric OH, $\mathrm{O}_{3}$ and $\mathrm{NO}_{3}$ reactivities within and above the boreal forest, Atmos. Chem. Phys., 15, 3909-3932, https://doi.org/10.5194/acp15-3909-2015, 2015.

Nemitz, E., Sutton, M. A., Schjoerring, J. K., Husted, S., and Paul, W. G.: Resistance modelling of ammonia exchange over oilseed rape, Agr. Forest Meteorol., 105, 405-425, 2000.

Nguyen, T. B., Crounse, J. D., Teng, A. P., St. Clair, J. M., Paulot, F., Wolfe, G. M., and Wennberg, P. O.: Rapid deposition of oxidized biogenic compounds to a temperate forest, P. Natl. Acad. Sci. USA, 112, E392-E401, 2015.

Niinemets, Ü., Fares, S., Harley, P., and Jardine, K. J.: Bidirectional exchange of biogenic volatiles with vegetation: emission sources, reactions, breakdown and deposition, Plant Cell Environ., 37, 1790-1809, https://doi.org/10.1111/pce.12322, 2014.

Park, J.-H., Goldstein, A. H., Timkovsky, J., Fares, S., Weber, R., Karlik, J., and Holzinger, R.: Active AtmosphereEcosystem Exchange of the Vast Majority of Detected Volatile Organic Compounds, Science, 341, 643-647, https://doi.org/10.1126/science.1235053, 2013.

Rannik, Ü.: On the surface layer similarity at a complex forest site, J. Geophys. Res.-Atmos., 103, 8685-8697, https://doi.org/10.1029/98JD00086, 1998.

Rantala, P., Taipale, R., Aalto, J., Kajos, M. K., Patokoski, J., Ruuskanen, T. M., and Rinne, J.: Continuous flux measurements of VOCs using PTR-MS - reliability and feasibility of disjunct-eddy-covariance, surface-layer-gradient, and surfacelayer-profile methods, Boreal Environ. Res., 19, 87-107, 2014.

Rantala, P., Aalto, J., Taipale, R., Ruuskanen, T. M., and Rinne, J.: Annual cycle of volatile organic compound exchange between a boreal pine forest and the atmosphere, Biogeosciences, 12, 5753-5770, https://doi.org/10.5194/bg-12-5753-2015, 2015.

Raventos-Duran, T., Camredon, M., Valorso, R., Mouchel-Vallon, C., and Aumont, B.: Structure-activity relationships to estimate the effective Henry's law constants of organics of atmospheric interest, Atmos. Chem. Phys., 10, 7643-7654, https://doi.org/10.5194/acp-10-7643-2010, 2010.

Rinne, J., Taipale, R., Markkanen, T., Ruuskanen, T. M., Hellén, H., Kajos, M. K., Vesala, T., and Kulmala, M.: Hydrocarbon fluxes above a Scots pine forest canopy: measurements and modeling, Atmos. Chem. Phys., 7, 3361-3372, https://doi.org/10.5194/acp7-3361-2007, 2007.

Rinne, J., Bäck, J., and Hakola, H.: Biogenic volatile organic compound emissions from the Eurasian taiga: current knowledge and future directions, Boreal Environ. Res., 14, 807-826, 2009.

Rinne, J., Markkanen, T., Ruuskanen, T. M., Petäjä, T., Keronen, P., Tang, M. J., Crowley, J. N., Rannik, Ü., and Vesala, T.: Effect of chemical degradation on fluxes of reactive compounds - a study with a stochastic Lagrangian transport model, Atmos. Chem. Phys., 12, 4843-4854, https://doi.org/10.5194/acp12-4843-2012, 2012. 
Sander, R.: Compilation of Henry's law constants (version 4.0) for water as solvent, Atmos. Chem. Phys., 15, 4399-4981, https://doi.org/10.5194/acp-15-4399-2015, 2015.

Saunders, S. M., Jenkin, M. E., Derwent, R. G., and Pilling, M. J.: Protocol for the development of the Master Chemical Mechanism, MCM v3 (Part A): tropospheric degradation of nonaromatic volatile organic compounds, Atmos. Chem. Phys., 3, 161-180, https://doi.org/10.5194/acp-3-161-2003, 2003.

Schallhart, S., Rantala, P., Nemitz, E., Taipale, D., Tillmann, R., Mentel, T. F., Loubet, B., Gerosa, G., Finco, A., Rinne, J., and Ruuskanen, T. M.: Characterization of total ecosystem-scale biogenic VOC exchange at a Mediterranean oak-hornbeam forest, Atmos. Chem. Phys., 16, 7171-7194, https://doi.org/10.5194/acp-16-7171-2016, 2016.

Smolander, S., He, Q., Mogensen, D., Zhou, L., Bäck, J., Ruuskanen, T., Noe, S., Guenther, A., Aaltonen, H., Kulmala, M., and Boy, M.: Comparing three vegetation monoterpene emission models to measured gas concentrations with a model of meteorology, air chemistry and chemical transport, Biogeosciences, 11, 5425-5443, https://doi.org/10.5194/bg-11-5425-2014, 2014.

Sogachev, A., Menzhulin, G., Heimannn, M., and Lloyd, J.: A simple three dimensional canopy - planetary boundary layer simulation model for scalar concentrations and fluxes., Tellus B, 54, 784-819, 2002.

Taipale, R., Kajos, M. K., Patokoski, J., Rantala, P., Ruuskanen, T. M., and Rinne, J.: Role of de novo biosynthesis in ecosystem scale monoterpene emissions from a boreal Scots pine forest, Biogeosciences, 8, 2247-2255, https://doi.org/10.5194/bg-82247-2011, 2011.

Tarvainen, V., Hakola, H., Hellén, H., Bäck, J., Hari, P., and Kulmala, M.: Temperature and light dependence of the VOC emissions of Scots pine, Atmos. Chem. Phys., 5, 989-998, https://doi.org/10.5194/acp-5-989-2005, 2005.

US EPA: Estimation Programs Interface Suite ${ }^{\text {TM }}$ for Microsoft ${ }^{\circledR}$ Windows, $\mathrm{v} 4.11$, available at: https://www.epa.gov/tscascreening-tools/download-epi-suitetm-estimation-programinterface-v411 (last access: 30 November 2017), 2017.

Wesely, M. L.: Parameterization of surface resistances to gaseous dry deposition in regional-scale numerical models, Atmos. Environ., 23, 1293-1304, 1989.

Williams, J., Crowley, J., Fischer, H., Harder, H., Martinez, M., Petäjä, T., Rinne, J., Bäck, J., Boy, M., Dal Maso, M., Hakala, J., Kajos, M., Keronen, P., Rantala, P., Aalto, J., Aaltonen, H., Paatero, J., Vesala, T., Hakola, H., Levula, J., Pohja, T., Herrmann, F., Auld, J., Mesarchaki, E., Song, W., Yassaa, N., Nölscher, A., Johnson, A. M., Custer, T., Sinha, V., Thieser, J., Pouvesle, N., Taraborrelli, D., Tang, M. J., Bozem, H., Hosaynali-Beygi, Z., Axinte, R., Oswald, R., Novelli, A., Kubistin, D., Hens, K., Javed, U., Trawny, K., Breitenberger, C., Hidalgo, P. J., Ebben, C. J., Geiger, F. M., Corrigan, A. L., Russell, L. M., Ouwersloot, H. G., Vilà-Guerau de Arellano, J., Ganzeveld, L., Vogel, A., Beck, M., Bayerle, A., Kampf, C. J., Bertelmann, M., Köllner, F., Hoffmann, T., Valverde, J., González, D., Riekkola, M.-L., Kulmala, M., and Lelieveld, J.: The summertime Boreal forest field measurement intensive (HUMPPA-COPEC-2010): an overview of meteorological and chemical influences, Atmos. Chem. Phys., 11, 10599-10618, https://doi.org/10.5194/acp-11-10599-2011, 2011.
Wolfe, G. M. and Thornton, J. A.: The Chemistry of AtmosphereForest Exchange (CAFE) Model - Part 1: Model description and characterization, Atmos. Chem. Phys., 11, 77-101, https://doi.org/10.5194/acp-11-77-2011, 2011.

Wolfe, G. M., Thornton, J. A., Bouvier-Brown, N. C., Goldstein, A. H., Park, J.-H., McKay, M., Matross, D. M., Mao, J., Brune, W. H., LaFranchi, B. W., Browne, E. C., Min, K.-E., Wooldridge, P. J., Cohen, R. C., Crounse, J. D., Faloona, I. C., Gilman, J. B., Kuster, W. C., de Gouw, J. A., Huisman, A., and Keutsch, F. N.: The Chemistry of Atmosphere-Forest Exchange (CAFE) Model - Part 2: Application to BEARPEX-2007 observations, Atmos. Chem. Phys., 11, 1269-1294, https://doi.org/10.5194/acp-111269-2011, 2011.

Zhou, L., Nieminen, T., Mogensen, D., Smolander, S., Rusanen, A., Kulmala, M., and Boy, M.: SOSAA - a new model to simulate the concentrations of organic vapours, sulphuric acid and aerosols inside the ABL - Part 2: Aerosol dynamics and one case study at a boreal forest site, Boreal Environ. Res., 19, 237-256, 2014.

Zhou, L., Gierens, R., Sogachev, A., Mogensen, D., Ortega, J., Smith, J. N., Harley, P. C., Prenni, A. J., Levin, E. J. T., Turnipseed, A., Rusanen, A., Smolander, S., Guenther, A. B., Kulmala, M., Karl, T., and Boy, M.: Contribution from biogenic organic compounds to particle growth during the 2010 BEACHON-ROCS campaign in a Colorado temperate needleleaf forest, Atmos. Chem. Phys., 15, 8643-8656, https://doi.org/10.5194/acp-15-8643-2015, 2015.

Zhou, P., Ganzeveld, L., Rannik, Ü., Zhou, L., Gierens, R., Taipale, D., Mammarella, I., and Boy, M.: Simulating ozone dry deposition at a boreal forest with a multi-layer canopy deposition model, Atmos. Chem. Phys., 17, 1361-1379, https://doi.org/10.5194/acp-17-1361-2017, 2017. 